\title{
LA FASE ATTARDATA IN CUI È RIMASTO IL CODICE CIVILE ITALIANO. UNA FELIX CULPA PER LA SCIENZA GIURIDICA DEGLI ANNI DIECI DEL NOVECENTO. IL GIURISTA COME INTELLETTUALE ${ }^{1}$
}

\author{
A FASE ATRASADA EM QUE PERMANECEU O CÓDIGO CIVIL ITALIANO. \\ UMA FELIX CULPA PARA A CIÊNCIA JURÍDICA DOS ANOS DEZ DO SÉCULO XX. O JURISTA \\ COMO INTELECTUAL
}

Italo Birocchi ${ }^{*}$

\begin{abstract}
Resumo:
$\mathrm{O}$ artigo examina a afirmação da ciência jurídica italiana no início do século XX. $\mathrm{O}$ processo de afirmação se inicia com a crise do modelo liberal fundado sobre o código civil, no final do século XIX, mas é sobretudo na década da Grande Guerra que chega à maturidade. As diversas disciplinas jurídicas tornam-se autônomas da civilística e especializam-se, dando suas próprias ferramentas expressivas próprias (revistas dos setores, manuais). Na medida em que se especializam, as diversas disciplinas afirmam ser unidas pelo método, que se afirma ser científico porque depurado da história e das ideologias. Por isto, reconhecem também a neutralidade. Porém, a alegada neutralidade da ciência jurídica não prejudica, e, ao contrário, implica que o jurista se volte à prática e esteja civilmente dedicado à política (teoriza-se, ao contrário, que a tarefa do jurista seja a de propor-se como legislador, para influenciar o social). Estas linhas gerais sobre o surgimento da ciência jurídica vêm, em particular, confrontadas por meio das figuras de seis grandes juristas em sua formação juvenil, considerados, precisamente, nas suas respectivas áreas disciplinares especializadas e na unidade do método (Asquini, Betti, Calamandrei, Jemolo, Mossa, Vassalli).

Palavras-chave: Ciência jurídica italiana do início do século XX. Especialização disciplinar. Unidade do método. Neutralidade da ciência jurídica. Crise do modelo jurídico liberal. O jurista como intelectual.
\end{abstract}

\begin{abstract}
Riassunto:
Il saggio esamina l'affermazione della scienza giuridica italiana agli inizi del Novecento. Il processo di affermazione prende avvio con la crisi del modello liberale fondato sul codice civile, verso la fine dell'Ottocento, ma è soprattutto nel decennio della Grande Guerra che giunge a maturazione. Le diverse discipline giuridiche si rendono autonome dalla civilistica e si specializzano dandosi strumenti espressivi propri (riviste di settore; manuali). Mentre si specializzano, le diverse discipline predicano di essere accomunate dal metodo, che si asserisce essere scientifico perché
\end{abstract}

Texto elaborado em razão do Colóquio "Cem Anos de Codificação Civil Brasileira", realizado na Faculdade de Direito da Universidade de São Paulo no mês de agosto de 2016.

* Professor de História do Direito na Universidade de Roma "La Sapienza". Foi pesquisador pela Universidade de Munique (1983-1984), pelo Merton College de Oxford (1984-1986), pelo Instituto Max Planck em Frankfurt a.M. (1988), pela Universidade de Barcelona (1993, 1996 e 2000), pela Universidade de Toulouse (2006) pelas Universidades de São Paulo e Buenos Aires (2007) e Madrid (2010). 
depurato dalla storia e dalle ideologie. Perciò se ne accredita anche la neutralità. E però l'asserita neutralità della scienza giuridica non toglie, ed anzi implica, che il giurista si rivolga alla pratica e sia impegnato civilmente e nella politica (si teorizza anzi che compito del giurista sia quello di proporsi come legislatore, per incidere nel sociale). Queste linee generali di emersione della scienza giuridica vengono in particolare confrontate attraverso le figure di sei grandi giuristi nella loro formazione giovanile, considerati appunto ciascuno nel rispettivo specialismo disciplinare e nell'unità del metodo (Asquini, Betti, Calamandrei, Jemolo, Mossa, Vassalli).

Parole chiave: Scienza giuridica Italian del primo novecento. Specialismi disciplinary. Unitá metodica. Neutralitá della scienza giuridica. Crisi del modello giuridico liberale. Il giurista come intellettuale.

\section{Prologo: l'ipotesi di lavoro}

Per la scienza giuridica italiana, gli anni che precedono e seguono immediatamente la grande guerra - grosso modo il secondo decennio del secolo - sono una fucina di riflessioni critiche e di idee, di studi e di proposte, di impegno nella vita civile oltre che all'interno delle istituzioni. Emerge allora la sua armatura tecnica e moderna, tanto raffinata quanto pratica; si costruisce la sua fama durevole, non solo tributata a qualche maestro di spicco, ma generalmente alla scuola italiana nelle diverse articolazioni disciplinari; si manifestano per il giurista i segni di un ruolo che, da specialista, lo mostra però capace di guardare con spirito d'insieme alle cose, se non all'universale.

È un'epoca che, al culmine del giolittismo, comprendendo al suo interno la forte cesura del conflitto mondiale, sotto il profilo storico-giuridico viene spontaneo ricollegare alla crisi conclamata del modello liberale, alla questione della rappresentanza politica, alle discussioni sulla legittimità dell'espansione coloniale e del rovesciamento delle alleanze internazionali, ai caratteri della legislazione di guerra e al problema immane dell'ordine giuridico nel tumultuoso periodo che seguì la fine del conflitto. Per fortuna disponiamo ormai di numerose indagini che hanno lumeggiato questi aspetti e che hanno anche proposto molte conoscenze nuove sui profili individuali dei giuristi, sugli strumenti di lavoro utilizzati, sul loro modus operandi (metodo, canali espressivi, ideologie). Qui si tenterà una riflessione problematica, essenzialmente uno schizzo, che attiene alla possibile configurazione del giurista come intellettuale.

\section{L'apertura del cantiere negli anni settanta dell'ottocento}

Quel decennio - crogiolo drammatico e fondamentale per la storia italiana (GENTILE, 2006, p. 78-79) - è il focus di un processo di costruzione avviato nel corso degli anni Settanta dell'Ottocento, da un lato con la critica e l'erosione del 
paradigma individualistico liberale, dall'altro con l'affermarsi del positivismo e dello sperimentalismo. Da qui l'emergere dell'istanza sociale, l'affiorare del discorso sul metodo, il guardare ecletticamente ad altri modelli.

In origine quel paradigma aveva operato col supporto del cemento ideologico dell'idea di nazione, che aveva animato l'élite alla guida del movimento risorgimentale e dunque anche i giuristi, i quali, secondo l'appropriato giudizio di Vittorio Scialoja, vi si erano confusi senza particolare caratterizzazione; (SCIALOJA, ano 4, n. 10,1911 , p. 8-9) ${ }^{2}$ l'esperienza francese, declinata in versione piemontese, ne era stata il referente essenziale. ${ }^{3}$ Il modello si era fatto Stato, grazie all'azione della Destra storica al governo (1861-76), che aveva appunto costruito su di esso le istituzioni e l'insieme degli assetti normativi della comunità nazionale. La presa di Roma, lo spostamento della capitale e la messa in sordina delle ulteriori spinte a inglobare nell'ordinamento i territori del nord-est avevano marcato la fine della fase risorgimentale, che si era riassunta in quell'orizzonte paradigmatico, d'altronde troppo stretto per una società civile frastagliata e diseguale e vieppiù animata da nuovi soggetti organizzati. È ben noto che, nel prendere terra, lo Stato immaginato andò allargando i compiti, cercando una propria strada al di là dei modelli e, sulle basi di un intenso lavorio di inchieste, cominciando a dotarsi di strumenti di intervento articolati e ad hoc. ${ }^{4}$ In sostanza crebbe l'apparato e l'azione dell'amministrazione e si moltiplicò la legislazione speciale, ma contemporaneamente si produssero due codici nei gangli fondamentali del commerciale (1882) e del penale (1889): i primi codici unitari nuovi di zecca, per così dire, dello Stato unitario.

2 Si cita dall'estratto: «da un canto i giuristi non avevano avuto nei moti del risorgimento soltanto la parte di giuristi; essi si ritrovavano in tutte le più svariate manifestazioni del patriottismo; d'altro canto all'opera giuridica stessa avevano partecipato anche non giuristi, sicché il comune lavoro non ammetteva precisa distinzione». Si può notare che nei programmi universitari di giurisprudenza, adottati all'indomani dell'Unità, una sorta di patriottismo giuridico avrà un posto d'onore nelle due giovani materie della Storia del diritto - che sarà dedicata appunto alla esperienza giuridica in Italia come tradizione unitaria sboccata infine nel Regno d'Italia - e del Diritto internazionale, in cui si affermò la scuola italiana imperniata sul principio di nazionalità.

3 Come nel 1860 (20-22 gennaio) annotava nel suo diario Federigo Sclopis, protagonista della vita intellettuale e politica nei decenni di transizione verso il Regno d'Italia, anche gli scettici e i critici si andavano convincendo che "piemontizzare" le province di nuova annessione era l'unica strada per arrivare a uno Stato unitario e indipendente, che non fosse «un novello assembramento di genti». SCLOPIS DI SALERANO, Federigo. Diario segreto (1859-1878). Torino: Deputazione subalpina di storia patria, 1959. p. 211.

4 Una lucidissima espressione critica verso l'uso di strumenti preconfezionati è quella del giovanissimo BRUGI, Biagio. I fasti aurei del diritto romano: studi preliminari. Pisa: Tipografia Vannucchi, 1879. p. 305-318, che contestualmente sosteneva la necessità di dedicarsi a studi specificamente legati alla nazione. Per un'originale analisi delle inchieste parlamentari nell'età postunitaria v. STOLZI, Irene. Le inchieste parlamentari. Un profilo storico-giuridico (Italia, 1861-1900). Milano: Giuffrè, 2015. v. 107. 
Tutto questo richiese e poté essere in qualche modo implementato attraverso un rinnovamento della scienza giuridica, che fu quasi una sua rifondazione. ${ }^{5}$ È significativo che all'inizio degli anni Ottanta fossero lanciate due iniziative volte a racchiudere in un complessivo orizzonte enciclopedico lo scibile giuridico articolato per voci ed istituti, nei quali la trattazione storica si coagulava e sfociava nel diritto vigente del nuovo Stato: due repertori dalla mole gigantesca, di per sé segno di consapevolezza del ruolo della scienza giuridica e delle sue ambizioni, programmati non solo per delimitare sommariamente gli spazi del diritto, ma anche per farne emergere in profondità i nessi ed i contenuti. ${ }^{6}$ Cominciò allora a tramontare il giurista polivalente, pervaso da ideali risorgimentali, eclettico eppur propenso ad operare attorno a un modello che si pretendeva universale (quello borgheseindividualistico) e che però, di fatto, esprimeva politicamente un regime oligarchico per il sistema elettorale censitario, per il bassissimo livello iniziale di alfabetizzazione e per la disomogeneità culturale e produttiva delle popolazioni incastonate nel sistema unitario. Si affermò correlativamente l'idea e il bisogno del giurista specializzato, studioso originale capace di dare impulso alla propria materia e perciò attivo all'interno di una disciplina autonoma (pur se legata alle altre).

Ai nostri occhi si apre l'immagine di un cantiere. Gli stessi due codici poc'anzi menzionati non erano un punto d'arrivo, come spesso la storiografia considera, (OPPO, 1993, pt. 1, p. 221) andando l'uno, il commerciale, a sostituire quello promulgato sì nel 1865 ma con l'esplicita intesa di lavorare subito a uno nuovo, e producendo l'altro, il penale, la prima unificazione del settore. Se proprio si vuol usare la metafora del punto di partenza e d'arrivo, la prima immagine appare più adatta. Erano codici pensati ex novo per dotare di istituti più aggiornati le rispettive materie - è il caso della cambiale, che finalmente ebbe una normativa moderna rispetto alla lettera di cambio d'Antico Regime -, sistemandole secondo una filosofia tanto precisamente esplicitata quanto dibattuta: codici che nacquero entrambi con infinite discussioni e tra i contrasti. Basti pensare al manifesto Troppo presto, di poco precedente al codice penale, con posizioni critiche che, nutrite del montante positivismo, andarono poi a rafforzarsi dopo la sua emanazione; ${ }^{7} \mathrm{e}$

Su questa rifondazione sono state opere collettive pioniere e sono tuttora fondamentali MAZZACANE, Aldo (Org.). I giuristi e la crisi dello Stato liberale in Italia fra otto e novecento. Napoli: Liguori, 1986 e MAZZACANE, Aldo; SCHIERA, Pierangelo (Org.). Enciclopedia e sapere scientifico: il diritto e le scienze sociali nell’Enciclopedia Juridica Italiana. Bologna: Il Mulino, 1990.

6 Si allude alla Enciclopedia giuridica italiana, ideata e diretta inizialmente da Pasquale Stanislao Mancini, e al Digesto italiano, diretto da Giuseppe Saredo, che inaugurarono le pubblicazioni nel 1884, raccogliendo nel primo volume i fascicoli precedentemente usciti (i due direttori furono presto sostituiti da Enrico Pessina e da Luigi Lucchini). Sul loro significato ora BIROCCHI, Italo. Enciclopedie giuridiche tra storia e valutazione scientifica. In: CONTE, Giuseppe (Org.). Evoluzione e valutazione della ricerca giuridica. Napoli: Edizioni Scientifiche Italiane, 2015a. p. 216-221.

7 Si rinvia agli ormai classici saggi ora raccolti in SBRICCOLI, Mario. Storia del diritto penale e della giustizia. Scritti editi e inediti (1972-2007). Milano: Giuffrè, 2009. v. 88, n. 1-2. (Per la storia pensiero 
basti rammentare l'atteggiamento radicale di colui che diventerà il maestro indiscusso della commercialistica del primo Novecento - Cesare Vivante - che ritenne sin dall'inizio errata la separazione del codice commerciale da quello civile. ${ }^{8}$

Un cantiere, appunto, nel quale a prima vista sembra di scorgere soprattutto il disordine: una certa vaghezza di direttrici ideali, una inconcludenza delle proposte, una opposizione di metodi nell'ampio ventaglio di orientamenti, che a un estremo predicavano l'avvento di una dogmatica depurata da sociologismi e, all'altro, di un sociologismo impermeabile alle astrazioni. Le furibonde bordate contro i criminalisti metafisici assestate dal giovane Enrico Ferri si incrociavano con le risposte altrettanto radicali contro "i semplicisti" del pugnace Lucchini. ${ }^{9}$ Ma osservando bene si tratta della confusione di apporti con cui sempre si presenta ogni fase di costruzione, che inizialmente si dirige alla critica dell'esistente e si nutre di voci discordi.

Ad accrescere l'impressione di dispersione sta poi la mancanza di quell'elemento coesivo forte che in precedenza era dato dagli ideali risorgimentali e dalla lotta per la laicità dello Stato. Non che quegli ideali fossero scomparsi, ma con la presa di Roma sembrava che essi si fossero per così dire trasfusi compiutamente nelle istituzioni dello Stato, conquistando stabilità e però anche perdendo forza mobilitante e coesiva. L'impegno civile dei giuristi si polarizzò sempre meno intorno a temi come l'autonomia dello Stato o la separazione dalla Chiesa, che divennero argomenti specifici di competenza dell'ecclesiasticista; quell'impegno si manifestò in nuove direzioni, non controllate da una ideologia univoca, talvolta effimere ma comunque in dialettica con gli orientamenti ideali legati ai soggetti che si affacciavano sulla scena politica (il radicalismo, il socialismo, il nazionalismo, lo stesso cattolicesimo con le sue organizzazioni di nuovo conio). Più oltre, e proprio negli anni che interessano qui, a complicare il quadro sopraggiunsero l'impresa in Libia e la prima guerra mondiale. Rinnovando il mito ottocentesco si affermò un nazionalismo complesso e ambiguo. Esso trovò simpatie presso i giuristi, che presero spesso parte alle discussioni, sia usando pienamente i ferri del mestiere, sia più frequentemente come divulgatori (di solito del verbo interventista): sempre visibili e protagonisti, comunque.

giuridico moderno), spec. I, p. 493-567, 591-623, e II, p. 819 ss e 903-980. Vedi inoltre COLAO, Floriana. Le scuole penalistiche. In: CAPPELLINI, Paolo et. al. (Org.). Il contributo italiano alla storia del pensiero. Diritto. Roma: Istituto della Enciclopedia Italiana, 2012. spec. 349-352 e MILETTI, Marco Nicola. La giustizia penale. In: CAPPELLINI, Paolo et. al. (Org.). Il contributo italiano alla storia del pensiero. Diritto. Roma: Istituto della Enciclopedia Italiana, 2012. p. 467-474.

8 Per tutti: LIBERTINI, Mario. Vivante, Cesare. In: BIROCCHI, Italo, et al. (Org.). Dizionario biografico dei giuristi italiani (XII-XX secolo). Bologna: Il Mulino, 2013. v. 2. p. 2.060.

9 FERRI, Enrico. I nuovi orizzonti del diritto e della procedura penale. Bologna: Zanichelli, 1881. (con successive edizioni ampliate, anche con titolo differente); LUCCHINI, Luigi. I semplicisti (antropologi, psicologi e sociologi) del diritto penale. Torino: Unione Tipografico-Editrice, 1886. 
In questo scenario il codice civile vigente, promulgato nel 1865 al culmine di quella "unificazione giuridica a vapore" che aveva costituito l'ossatura forte dell'avvio del regno, era avvertito come "immobile" e dunque "attardato". Esplicito in questo senso l'editoriale di presentazione della Rivista di diritto commerciale che, firmato dai due direttori Cesare Vivante e Angelo Sraffa, inaugurava le pubblicazioni nel 1903: non solo perché quel codice non racchiudeva le regole per le relazioni recentemente indotte dallo sviluppo economico, come ad esempio i nuovi rapporti di lavoro industriali, ma perché non rappresentava più, nel suo complesso, la "costituzione" giuridica della società civile che, come si sa, è stata la ragione prima della grande fortuna ottocentesca del modello napoleônico. ${ }^{10}$ Un ritardo ormai irrimediabile col ricorso a semplici aggiustamenti, eppure, in fondo, una colpa felice, perché consentiva alla scienza giuridica di esprimersi appieno, come interprete della "natura delle cose" - il sintagma circolava frequentemente in seno alla giuscommercialistica, ma non solo ${ }^{11}$ - e, lo si vedrà, addirittura come legislatrice, fornendo il supporto essenziale per l'emanazione della legislazione speciale. E non è un caso che questi concetti si ritrovino nel manifesto pubblico con cui due cultori della dottrina commerciale particolarmente sensibili alla pratica lanciavano la loro rivista, che si affermò come strumento di elaborazione e di comunicazione di un'intera generazione di giuristi: ${ }^{12}$ in quella materia, particolarmente, era vivissima la coscienza che occorresse schivare le cristallizzazioni scolastiche e prestare invece orecchio agli istituti allora in fase di costruzione in Europa, secondando lo sviluppo degli scambi e più ambiziosamente dando corso all'idea di “progresso". (VIVANTE; SRAFFA, 1903, p. I-II).

\section{Lo specialismo e l'appartenenza disciplinare}

La scienza giuridica non è una categoria astratta. Nel secondo decennio del Novecento protagonista è la seconda generazione che opera dopo l'Unità, cioè i giuristi nati negli anni attorno al compimento dell'unificazione. ${ }^{13} \mathrm{E}$ la generazione che

$\overline{10}$ È un'affermazione pacifica nella storiografia, anche di parte civilistica (IRTI, Natalino. L'età della decodificazione. Milano: Giuffrè, [1979]. p. 6; SALVI, Cesare. La giusprivatistica fra codice e scienza. In: SCHIAVONE, Aldo (Org.). Stato e cultura giuridica in Italia dall'Unità alla Repubblica. Roma-Bari: Laterza, 1990. p. 235; RODOTÀ, Stefano. La libertà e i diritti. In: ROMANELLI, Raffaele (Org.). Storia dello stato italiano: dall'unità a oggi. Roma: Donzelli, 1995. p. 302-303). Non coincidente, ma contigua, è la questione se i codici, e soprattutto il codice civile, sotto la vigenza dello Statuto Albertino rientrassero tra le fonti del diritto costituzionale, secondo la tesi di Santi Romano (si rinvia a UNGARI, Paolo. Per la storia dell'idea di codice. Quaderni Fiorentini: per la storia del pensiero giuridico moderno, Milano, v. 1, p. 207227, 1972. p. 210-212.

11 Specialmente nella dottrina che da Vivante arriva ad Ascarelli: v. di recente PELLICCIOLI, Luca. Natura delle cose e metodo giuridico: il "diritto naturale" dei giuristi. Pisa: ETS, 2015. p. 45-83.

12 Fu, per esempio, un riferimento per la Rivista di diritto processuale civile (1924): v. oltre, nt. 74*.

13 Per ricordare qualche nome indicativo, oltre al più vecchio Lucchini: Scialoja, Ruffini, Vivante, Riccobono, Orlando, Bonfante, Venezian, Mortara, Ferri, Brugi, Lessona, Sraffa, fino ai più giovani Anzilotti, 
è andata in cattedra pubblicando lavori originali (una o più monografie e saggi) su temi inerenti la propria materia. Lo specialismo è il suo primo carattere e ne costituisce un riscontro decisivo la modalità di reclutamento che si afferma ora in prevalenza nella pratica: per concorso per titoli specifici e non per qualche saggio raccogliticcio o per "chiara fama", come invece avveniva per lo più nei primi tempi di applicazione della legge organica sull'istruzione (13 novembre 1859, cosiddetta legge Casati), allorché dominava la decisione ministeriale, direttamente o tramite la nomina delle commissioni concorsuali (anche tramite il Consiglio Superiore della Istruzione Pubblica). ${ }^{14} \mathrm{Ma}$, almeno nelle condizioni storiche dell'Italia del tempo, lo specialismo non avrebbe potuto pensarsi senza un corrispondente sviluppo delle singole discipline, sicché non era meramente un carattere riguardante il giurista quale individuo, bensì in quanto operasse e fosse riconosciuto all'interno di una comunità distinta in senso soggettivo e materiale: un corpo dotato di relazioni tra i suoi membri, di specifiche tradizioni di cooptazione, di propri contenuti, di strumenti espressivi e quindi di un bagaglio formativo particolare, anche se non necessariamente di un metodo separato da quelli impiegati dalle altre discipline giuridiche, per quella idea di unitarietà della scienza che non venne mai meno. Un corpo, in una parola, fornito di un proprio "statuto" identitario.

Come è naturale, lo specialismo si espresse in primo luogo attraverso monografie dedicate, sviluppate sulle fonti e sullo strumentario particolare di cui ogni disciplina andava provvedendosi; ma lo si apprezza soprattutto guardando ad altri generi letterari, che mettevano in evidenza non solo l'individualità del giurista, ma anche la sua appartenenza al corpo di studiosi della materia. Si allude alle riviste di settore, ai manuali e trattati (si vedrà che il discrimine tra queste denominazione è abbastanza labile), alle

Chiovenda, Alfredo Rocco e Santi Romano.

14 Le forme di reclutamento, sostanzialmente sotto l'egida ministeriale, consentivano sia di filtrare i professori a seconda della ideologia risorgimentale, sia di risolvere il problema di coprire effettivamente gli insegnamenti: all'inizio, infatti, non c'erano che pochissimi professori ordinari a cui rivolgersi per costituire le commissioni giudicatrici che avrebbero dovuto essere formate da esperti. Anche allorché la cattedra era assegnata per concorso, era dunque necessario l'intervento del ministero per la nomina dei commissari (talvolta scelti dai ranghi ministeriali, o semplici professori di diritto con una lontana affinità, o addirittura liberi docenti o dottori aggregati). Per gli anni immediatamente successivi al 1860 i fascicoli personali dei professori universitari raccontano di improvvisati candidati che si proponevano per una cattedra qualunque nelle più svariate materie (di solito quelle più "giovani": Diritto costituzionale, Enciclopedia giuridica, Diritto internazionale, Filosofia del diritto, Storia del diritto, Diritto amministrativo o Scienza dell'amministrazione), allegando trascorse partecipazioni all'esperienza del 1848 o del 1859, qualche scrittura e riservandosi di presentare un piano didattico in caso di assegnazione della titolarità di un corso (in Archivio Centrale dello Stato, Ministero della Istruzione pubblica, Personale, [1860-1880], ad nomen). È dagli inizi degli anni Ottanta che la proposta dei nominativi per le commissioni concorsuali passa alle Facoltà e, dal 1890, ai docenti ordinari della materia: le linee dei provvedimenti normativi sono illustrate in FOIS, Giuseppina. Reclutamento dei docenti e sistemi concorsuali, dal 1860 a oggi. In: BRIZZI, Gian Paolo; DEL NEGRO, Piero; ROMANO, Andrea (Org.). Storia delle Università in Italia. Messina: Sicania, 2007. v. 1. p. $461-463$. 
prolusioni e ai repertori specializzati. Se ne parlerà qui di seguito in forma sintetica, con l'avvertenza che altre forme letterarie, attualmente considerate "minori", venivano utilizzate nella stessa direzione con pari dignità. ${ }^{15}$

a) Quanto alle riviste, la loro fioritura dopo l'Unità fu abbondante pur se spesso effimera e costituì un importante veicolo per divulgare la cultura giuridica come cemento pratico del sociale; per lo più erano di impronta generalista mentre promotori e destinatari furono soprattutto gli operatori che a vari livelli maneggiavano la legislazione e la giurisprudenza. ${ }^{16}$ La rivista giuridica non era collegata a un centro di elaborazione, bensì raccoglieva e faceva circolare temi e questioni che emergevano nell'esercizio quotidiano del diritto, sicché il carattere pratico improntava anche i periodici come la precoce Rivista amministrativa del Regno (pubblicata a partire dal 1850), che pure nascevano con riferimento a una materia specifica. (ROSSI, 2006, p. 3-130). Si spiega così come la specializzazione riguardasse branche emergenti nella vita sociale e pertanto oggetto di interventi legislativi frequenti e di interpretazioni controverse e problematiche: si pensi al diritto ferroviario - intreccio di diritto privato e pubblico, di amministrativo e commerciale - verso cui si indirizzarono diverse iniziative editoriali periodiche e per il quale si propose addirittura di istituire un insegnamento universitario: ${ }^{17}$ testimonianza forte di una concezione positivistica che nel considerare il diritto quale regola che aderisce ai fatti economico-sociali rischia di scadere nella frammentazione minuta.

È vero che si ebbero anche riviste durevoli e specialistiche, ma in settori con tradizione storica di autonomia, come il comparto criminale ${ }^{18}$ e quello mercantile, ${ }^{19}$ o laddove, come nell'ecclesiastico, l'urgere della questione politica dei rapporti tra Stato e Chiesa suscitava discussioni particolari di natura teoretica e, d'altra parte, sollecitava

15 V. le considerazioni di CALAMANDREI, Piero. Gli studi di diritto processuale in Italia nell'ultimo trentennio (I ediz. 1941). In: Scritti sul processo civile. Padova: Cedam, 1947a. v. 5. p. 123, formulate per la dottrina processualcivilistica ma certamente generalizzabili.

16 Contro un siffatto pragmatismo privo di elaborazione, puntualissima la critica di un avvocato di vaglia, oltre che politico e scrittore nonché direttore o collaboratore di diverse riviste giuridiche, come GIURIATI, Domenico. Arte forense... Torino: Roux e Favale, 1878. p. 101.

17 MANSUINO, Carlo (Org.). Periodici giuridici italiani: 1850-1900: repertorio. Milano: Giuffrè, 1994, utile in generale per il discorso svolto nel testo. Credette fortemente nell'autonomia del diritto ferroviario un futuro maestro del diritto commerciale come MANARA, Ulisse. Il diritto ferroviario: formazione, carattere, partizione. Archivio Giuridico, [S.1.], v. 40, fasc. 1-2, 1888. p. 88-131, spec. p. 97, 106 s., 120 s. Cfr. BRACCIA, Roberta. Le strade ferrate: il silenzio dei codici unitari e le parole degli avvocati. In: BORSACCHI, Stefano; PENE VIDARI, Gian Savino (Org.). Avvocati protagonisti e rinnovatori del primo diritto unitario: storia dell'avvocatura in Italia. Bologna: Il Mulino, 2014. p. 385-409.

18 Rivista penale, fondata nel 1874 da Luigi Lucchini; Archivio di psichiatria, antropologia criminale e scienze penali, fondato da Cesare Lombroso e Raffaele Garofalo nel 1880, che ebbe anche Ferri tra i successivi direttori; La scuola positiva, fondata nel 1891 da Enrico Ferri, Giulio Fioretti, Raffaele Garofalo e Cesare Lombroso.

19 Il diritto commerciale, fondato nel 1883 da David Supino e da Filippo Serafini; Annuario critico della giurisprudenza commerciale, inaugurato nel 1883 sotto la direzione di Ercole Vidari e Leone Bolaffio. 
la depurazione della materia da contaminazioni extragiuridiche; ${ }^{20}$ è comunque sin troppo facile rilevare la loro mancanza in settori non solo "giovani" come l'internazionale, il costituzionale, la procedura civile e la storia del diritto, ma a lungo anche in una materia quale il diritto romano, fattasi ormai disciplina storica. ${ }^{21}$

In effetti per quasi tutto l'Ottocento il giurista trovava naturale affidare i propri saggi a riviste generaliste come l'Archivio giuridico (dal 1868) e la Rivista italiana per le scienze giuridiche (dal 1886), o addirittura, per i temi dai risvolti giuridico-politici, a periodici culturali. ${ }^{22}$ La sterzata verso riviste di settore, espressione di elaborazione, strumento di aggiornamento internazionale e nel contempo palestra di discussione, si ha diffusamente dai primi del Novecento. È del 1903 la Rivista di diritto commerciale, che, fondata da Vivante e Sraffa, non solo supera immediatamente «il ben più modesto precedente costituito dal Diritto commerciale» - ormai ventennale ${ }^{23}$-, ma rinnova la materia aprendola compiutamente al dibattito europeo e, riservando sin dal titolo un posto particolare alle obbligazioni, facendone un polo di attrazione anche per i civilisti, i lavoristi e i processualcivilisti. ${ }^{24}$ Segue, nel 1906, la Rivista del diritto internazionale, nella quale Anzilotti, critico delle costruzioni giusnaturalistiche ancora presenti nella dottrina italiana, ammiratore della pubblicistica tedesca, attentissimo alla pratica, imprime la svolta positivista, chiudendo la partita con la scuola manciniana e con quella generazione di transizione che le era subentrata verso gli anni Ottanta. ${ }^{25} \mathrm{Nel} 1909$ comincia

20 È nota la pagina del giovane RUFFINI, Francesco. L'indirizzo odierno del diritto ecclesiastico in Italia. In: . Scritti giuridici minori. Milano: Giuffrè, 1936. v. 1. p. 49-67. Nel 1890 apparve la Rivista di diritto ecclesiastico, fondata da Guglielmo Caselli e da Serafino Giustiniani. Una silloge di testi che testimoniano il dibattito sullo statuto metodologico e sull'insegnamento del diritto ecclesiastico a fine Ottocento è contenuta in MIELE, Manlio (Org.). Gli insegnamenti del diritto canonico e del diritto ecclesiastico dopo l'Unità d'Italia. Bologna: Il Mulino, 2015. p. 341 e ss.

21 Il Bullettino dell 'Istituto di diritto romano, fondato da Vittorio Scialoja, inaugurò le pubblicazioni nel 1888: nel loro insieme (Istituto e Bullettino) furono, come è noto, il fortino da cui il giurista poté muovere per esercitare per quasi un cinquantennio una indiscussa supremazia sulla scienza giuridica.

22 È il caso della rivista Cuore e critica (fondata nel 1887) alla quale collaborarono personaggi come Giovanni Bovio, Carlo Lessona, Napoleone Colajanni e Filippo Turati.

23 V. sopra, nt. 22*. La citazione nel testo è di FURGIUELE, Giovanni. La "Rivista di diritto civile" dal 1909 al 1931. Quaderni Fiorentini: per la storia del pensiero giuridico moderno, Milano, v. 16, p. 519-630, 1987. p. 526 nt. 24.

24 Alla rivista di Vivante e Sraffa nel primo ventennio dopo la sua fondazione è dedicato il saggio di LIBONATI, Bernardino et al. La rivista di diritto commerciale (1903-1922). Quaderni Fiorentini: per la storia del pensiero giuridico moderno, Milano, v. 16, p. 343-374, 1987. Sulla collaborazione dei processualcivilisti alla stessa rivista pure nel primo ventennio (e cioè prima della fondazione della Rivista di diritto processuale civile) v. il saggio di PROTO PISANI, Andrea. Materiali per uno studio dei contributi processualcivilistici della "Rivista di diritto commerciale" (1903-1923). Quaderni Fiorentini: per la storia del pensiero giuridico moderno, Milano, v. 16, p. 375-440, 1987.

25 Anzilotti fondò la rivista nel 1906 insieme a due pratici come Arturo Ricci Busatti e a Leone Adolfo Senigallia, apprestando così una palestra di discussioni che personalmente aveva inaugurato sin dal suo primo insegnamento di Diritto internazionale privato presso l'Istituto Cesare Alfieri di Firenze (1893). Sul trapasso dalla scuola manciniana a quella positiva v. MURA, Eloisa. All'ombra di Mancini: la disciplina 
le pubblicazioni la Rivista di diritto civile animata da Alfredo Ascoli, la cui apparizione ben si connette con l'esigenza di rinnovamento che il suo principale artefice espresse nella coeva prolusione pisana (FURGIUELE, 1987, p. 520). Nel Programma con cui apriva le pubblicazioni, il periodico civilista si indirizzava agli intellettuali, sottolineando la necessità di dare impulso a opere nazionali, che attingessero alle «fonti della vita, dei bisogni, dei costumi, dei sentimenti italiani» (CAZZETTA, 2013, p. 24). Nello stesso 1909 vide la luce la Rivista di diritto pubblico, che faceva seguito alle precedenti prove di Archivio di diritto pubblico (dal 1891 e ancora dal 1902); ${ }^{26}$ diretta da un gruppo di giuristi tra i quali spicca la figura di Orlando, significativamente essa metteva al centro lo Stato, ovviamente nella forma depurata e astratta predicata dal giurista siciliano (CASSESE, 1987, v. 16, p. 501-518). Poco dopo, nel 1910, inaugurava inoltre le pubblicazioni la Rivista di diritto e procedura penale, sotto la direzione di Zerboglio e Florian, cui si affiancò nel 1914 Raffaele Garofalo. Nel breve ma succoso programma pubblicato in apertura, i due penalisti dichiaravano di voler dare vita a uno strumento moderno e rapido, diretto «a lumeggiare i principii, avvicinandoli e cimentandoli ai fatti quotidiani, più che a svilupparli astrattamente»; l'indirizzo era positivista e mirava a cogliere «il processo di svolgimento delle teorie e delle leggi penali in sé e nelle loro applicazioni, senza eccessive generalizzazioni aprioristiche», con la speranza «di trovarsi sempre in armonia colle condizioni della cultura, i bisogni mediati ed immediati della Società e dello Stato» (FLORIAN; ZERBOGLIO, 1910, v. 1, p. 1-2). Più ritardata, addirittura negli anni Venti, l'apparizione di riviste scientifiche stabili di settore nell'ambito della procedura civile e della storia del diritto per ragioni che, essenzialmente, pare di poter ricondurre, nel primo caso, a una tradizione di legami col civile e a un intreccio contrastato di rapporti tra $\mathrm{i}$ maestri più in vista della disciplina nei primi due decenni del secolo (Mortara, che peraltro dirigeva la Giurisprudenza italiana, Lessona e Chiovenda). E, nel secondo caso, all'idea a lungo persistente che la storia, mentre pure richiedeva raffinati e specifici requisiti di indagine, fosse connessa con il complesso del diritto vigente e non le si addicesse un periodico ad hoc: ${ }^{27}$ intesa come antecedente necessario del diritto positivo, in questo si

internazionalistica in Italia ai suoi albori. Pisa: ETS, 2017. Sulla rivista: GAJA, Giorgio. Le prime annate della "Rivista di diritto internazionale" ed il rinnovamento del metodo. Quaderni Fiorentini: per la storia del pensiero giuridico moderno, Milano, v. 16, p. 485-499, 1987; SALERNO, Francesco. La rivista e gli studi di diritto internazionale nel periodo 1906-1943. Rivista di diritto internazionale, Milano, v. 90, n. 2, 2007. p. 305-343); PASSERO, Laura. Dionisio Anzilotti e la dottrina internazionalistica tra otto e novecento. Milano: Giuffrè, 2010. p. 263-325.

26 Sulla significativa esperienza dell'Archivio di diritto pubblico e in particolare sul Programma esposto dal suo fondatore Orlando v. CIANFEROTTI, Giulio. Il pensiero di V. E. Orlando e la giuspubblicistica italiana fra ottocento e novecento. Milano: Giuffrè, 1980. p. 190 e ss.

27 La Rivista di diritto processuale civile, fondata da Carnelutti e Chiovenda, è del 1924 (v. DENTI, Vittorio; TARUFFO, Michele. La rivista di diritto processuale civile. Quaderni Fiorentini: per la storia del pensiero giuridico moderno, Milano, v. 16, p. 631-664, 1987). La Rivista di storia del diritto italiano, pubblicata per 
scioglieva quale perno del discorso globale sulla identità della nazione infine costituitasi in Stato unitario (SPINOSA, 2013, p. 341-384).

b) Quanto ai manuali, il loro significato è duplice: da un lato segnalavano di volta in volta il modo in cui il singolo studioso interpretava la disciplina e in qualche modo la propria collocazione al suo interno; dall'altro, nel loro insieme, delimitavano gli spazi della materia, segnavano i confini ma anche le interrelazioni con le altre, indicavano le metodologie dominanti. ${ }^{28}$ Per questi profili veramente si può dire che la loro apparizione coincide con il processo di specificazione delle materie e di affermazione della figura del giurista specializzato. Non inganni la fama che accompagna tale tipo letterario, quale genere dedicato in via esclusiva all'insegnamento: come spesso capita, la fama è un pregiudizio di comodo, che semplifica e però anche deforma la realtà. In effetti, nella sua storicità la funzione di questo genere letterario dipende dalla vita della materia e dal rapporto con le altre. ${ }^{29}$ Per quanto qui interessa, l'uso fu certamente anche didattico, in quanto il manuale disegnava il circuito della materia entro cui poi le lezioni erano ritagliate e si potevano selezionare i temi e i livelli della preparazione studentesca; ma il testo non parlava solo al discente, bensì pure ai colleghi della disciplina e a quelli delle altre materie giuridiche, talora con ambizioni di originalità preventivamente dichiarate. ${ }^{30}$ Perciò non di rado si presentavano nella veste di trattati e magari ne portavano pure il nome, come era avvenuto nello scorcio dell'Ottocento soprattutto per le nuove discipline - si pensi alla Storia del diritto italiano, al diritto processuale civile o al Diritto internazionale ${ }^{31}-\mathrm{o}$

iniziativa di Mochi Onory e Viora e diretta inizialmente da Brandileone, Tamassia e Calisse è del 1928 (su di essa VIORA, Mario Enrico. Indice del cinquantennio (1928-1977). Rivista di storia del diritto italiano, Roma, v. 50, 1977. p. I-XXX).

28 Questi profili sono ad esempio esplicitati nel proprio manuale di Pandette da Ferrini nella prefazione all'edizione del 1900 (FERRINI, Contardo. Diritto penale romano: teorie generali. Milano: Ulrico Hoepli, 1899. p. VII-XI).

29 In relazione a quanto detto nel testo, in CHAMBOST, Anne-Sophie. Premiers Jalons pour une histoire des manuels de droit. In: CHAMBOST, Anne-Sophie (Org.). Histoire des manuels de droit. Une histoire de la littérature juridique comme forme du discours universitaire. Paris: Lextenso LGDJ, 2014b, si possono leggere la provocazione iniziale di JAMIN, Christophe. Le droit des manuels de droit ou l'art de traiter la moitié du sujet. In: CHAMBOST, Anne-Sophie (Org.). Histoire des manuels de droit. Une histoire de la littérature juridique comme forme du discours universitaire. Paris: Lextenso LGDJ, 2014. p. 9-24 e il saggio della stessa CHAMBOST, Anne-Sophie. Premiers Jalons pour une histoire des manuels de droit. In: CHAMBOST, Anne-Sophie (Org.). Histoire des manuels de droit. Une histoire de la littérature juridique comme forme du discours universitaire. Paris: Lextenso LGDJ, 2014b. p. 25-32.

30 È il caso dei due manualetti di una personalità del resto assai particolare come quella di Ferrini, con gli intenti enunciati nelle rispettive prefazioni: FERRINI, Contardo. Il Digesto. Milano: Ulrico Hoepli, 1893 e FERRINI, Contardo. Diritto penale romano: teorie generali. Milano: Ulrico Hoepli, 1899.

31 Rispettivamente: PERTILE, Antonio. Storia del diritto italiano dalla caduta dell'impero romano alla codificazione. Padova: Salmin, 1871; MATTIROLO, Luigi. Elementi di diritto giudiziario civile italiano. Torino: Bocca, 1875-80. 6 v. (che dalla seconda edizione prese il nome di Trattato); CARNAZZA AMARI, Giuseppe. Elementi di diritto internazionale. Catania: Crispo e Russo, 1866-1874. 2 v. - Maiser i due volumi furono ripubblicati insieme nel $1875 \mathrm{col}$ titolo di Trattato, Milano: Maisner; cfr. MURA, Eloisa. 
per quelle in cui era forte l'esigenza di ammodernamento. ${ }^{32}$ Non stupisce pertanto che nel genere manualistico/trattatistico si impegnassero spesso le forze fresche (Gianturco e Santi Romano, Ferrini e Bonfante, Calisse e Solmi, Mortara e Chiovenda, Fiore e Perassi, a mo' d'esempio), o addirittura, con qualche ingenuità, i neofiti, animati dalla sete di costruire.

Tra il primo ed il secondo decennio del Novecento questo lavorio di individualizzazione si assesta. ${ }^{33}$ Erano comparse due fortunate collane di manuali, l'una inaugurata nel 1886 dall'editore Barbèra, l'altra una dozzina d'anni dopo dalla Società editrice libraria, che proposero volumetti essenziali per tutte le materie del curriculum giuridico universitario e per alcune di quelle opzionali; quasi tutti ebbero numerose edizioni e ristampe (MECCA, 2013, p. 157-203). Gli autori erano per lo più di gran nome e alcuni, come Brugi e Pareto, parteciparono all'una e all'altra impresa. ${ }^{34}$ Proseguiva intanto l'elaborazione di libri istituzionali e di "corsi", che si avvalevano di un circuito di contenuti ormai collaudato (magari reinterpretati, aggiornati, ridotti rispetto alle matrici) o che scendevano nei particolari se finalizzati ad insegnamenti esegetici o di approfondimento. Continuò poi, come ovvio, l'interscambio tra la trattatistica di sintesi e le altre forme con cui ogni disciplina si esprimeva, come dichiarava apertamente Vivante allorché sottolineava la funzione di arricchimento e di aggiornamento che la Rivista di

All'ombra di Mancini: la disciplina internazionalistica in Italia ai suoi albori. Pisa: ETS, 2017.

32 VIVANTE, Cesare. Trattato teorico-pratico di diritto commerciale. Torino: F.lli Bocca, 1893-1902. 4 v.; per il diritto romano ricche informazioni in STOLFI, Emanuele. Studio e insegnamento del diritto romano dagli ultimi decenni dell'Ottocento alla prima guerra mondiale. In: BIROCCHI, Italo; BRUTTI, Massimo (Org.). Storia del diritto e identità disciplinari: tradizioni e prospettive. Torino: Giappichelli, 2016. p. 21 ss. e 31 ss.; per la civilistica, all'indomani della fase strettamente esegetica, v. NARDOZZA, Massimo. Manualistica e cultura del codice civile in Italia tra otto e novecento. Roma: Aracne, 2012. (con particolare riferimento alle Istituzioni di Pacifici Mazzoni, Gianturco, Brugi, Simoncelli e Nicola Coviello); per il diritto internazionale, dalle prime prove degli anni Sessanta, MURA, Eloisa. All'ombra di Mancini: la disciplina internazionalistica in Italia ai suoi albori. Pisa: ETS, 2017. Sull'interscambio tra materiali didattici (dispense, corsi litografati) ed elaborazione scientifica v. CALAMANDREI, Piero. Gli studi di diritto processuale in Italia nell'ultimo trentennio (I ediz. 1941). In: Scritti sul processo civile. Padova: Cedam, 1947a. v. 5. p. 118.

33 Nel 1909 parlava di "diluvio di manuali" VIDARI, Ercole. Compendio di diritto commerciale italiano. Milano: Ulrico Hoepli, 1910, prefazione alla quarta edizione datata luglio 1909.

34 Per Barbèra furono stampate 37 opere (alcune in più tomi; talvolta con mutamenti di nome da un'edizione all'altra), mentre la Società editrice libraria ne produsse 29 (nella collana apparve inoltre una edizione del Digesto). Di assai minor rilievo appare la serie di manuali per il diritto pubblicata da Hoepli a partire dal 1890, sia perché risentiva di un progetto eterogeneo (una parte dei testi, assai brevi, era destinata agli Istituti tecnici e l'impostazione era elementare), sia perché non comprendeva tutte le principali materie del curriculum universitario, sia per il minor prestigio degli autori (ma con qualche eccezione). Accanto a queste collane, dalla struttura agilissima, la corsa ai manuali si nutrì di altre iniziative; così nei secondi anni Ottanta, per la UTE di Torino e sotto la direzione di Giuseppe Saredo uscirono diversi testi raggruppati nella Raccolta di manuali di diritto, economia politica, di statistica e di finanza (spiccano l'innovativo Manuale della procedura civile di Lodovico Mortara, 1887, 2 voll., e il SALVIOLI, Giuseppe. Manuale di storia del diritto italiano. Torino: Unione tipografico-editrice, 1890. 
diritto commerciale, da lui stesso diretta, svolgeva rispetto al suo Trattato (VIVANTE, 1904, v. 3, p. iniziale non numerata).

La specializzazione comunque non si fermava: gli anni Dieci, in particolare, sono un laboratorio permanente per quanto riguarda il diritto del lavoro - difficile da organizzare in un manuale e tuttavia al centro delle discussioni per quanto riguarda le strutture socio-produttive, i contratti collettivi e la giurisdizione ${ }^{35}-$, e il diritto coloniale, legato alle ideologie e alle pratiche espansionistiche che, dopo i rovesci di fine secolo, si riattizzarono attorno agli anni dell'impresa libica (1911). ${ }^{36}$

c) Lo strumento delle prolusioni ha molte facce: inaugura la didattica, ma è anche il momento solenne col quale si presenta il titolare della cattedra, che normalmente sceglie un tema di attualità o un nodo metodologico, magari al di fuori del corso; ha una risonanza speciale e un pubblico assai più vasto del novero degli studenti usuali, per il semplice fatto che se ne farà la stampa, sia in qualche pubblicazione miscellanea, sia in estratto; è insomma una conferenza-manifesto, legata all'insegnamento ma collocata all'esterno, che partecipa (o può partecipare) all'attività scientifica. ${ }^{37}$ Allorché il nesso tra didattica e ricerca è vivo, l'ambiguità delle prolusioni ne è giusto una espressione speciale ed è proprio quel che fondamentalmente accadde nel cantiere che stiamo visitando. Con una particolarità rimarchevole: ed è, ancora, l'accentuato e ricorrente interesse a riflettere

35 Si rinvia a CAZZETTA, Giovanni. Il lavoro. In: CAPPELLINI, Paolo et. al. (Org.). Il contributo italiano alla storia del pensiero. Diritto. Roma: Istituto della Enciclopedia Italiana, 2012. p. 422-429. Di lì a pochi anni l'imponente mole di proposte verrà inglobata dal fascismo all'interno dell'organizzazione corporativa: nacque, appunto, il diritto corporativo, impartito nell'omonimo insegnamento e con una grande fioritura di manuali.

36 Spiccano, per l'importanza degli autori, i corsi di lezione, rispettivamente tenuti alla Bocconi di Milano e al Cesare Alfieri di Firenze da Enrico Catellani (sulla storia, la politica e il diritto coloniale, pubblicati in diversi anni a partire dal 1910) e da Santi Romano (1918), come pure i corsi di un cultore particolarmente sistematico (era di scuola orlandiana) come Umberto Borsi, i cui Studi di diritto coloniale uscirono nel 1917-1918 (il Corso e i Principi sono invece della fine degli anni Venti e Trenta). Ma sono molto importanti anche i lavori degli specialisti pratici, di solito magistrati temporaneamente inviati nei territori coloniali, a cominciare da Mariano D'Amelio, che costruì la sua fortunata carriera in Africa, a Ranieri Falcone, a William Caffarel, a Salvatore Messina sr., a Massimo Colucci, a Carlo Conti Rossini (per le opere si rinvia al Dizionario biografico dei giuristi italiani, cit., ad nomen). V. anche oltre, su nt. 79*.

37 Come gli studiosi di letteratura si indirizzano anche a riflettere sul paratesto, così verrebbe voglia di approfondire il complesso delle informazioni che attorniano il contenuto della prolusione, proprio per il volto multiforme di questo genere letterario. A volte, ad esempio, i carteggi e i documenti d'archivio, oppure lo stile degli apparati di note consentono di apprendere il lungo lavorio della preparazione (è il caso della celeberrima prolusione milanese di Betti del 1927), come pure, al contrario, la frettolosa attività dedicata a certe altre prove inaugurali, che spiega certa sciatteria dei contenuti. Nella storiografia recente si segnalano Le prolusioni dei civilisti. Napoli: Edizioni Scientifiche Italiane, 2012. v. 1-3; CAZZETTA, Giovanni. Prolusioni, prelezioni, discorsi: l'identità nazionale nella retorica dei giuristi. In: . (Org.). Retoriche dei giuristi e costruzione dell'identità nazionale. Bologna: Il Mulino, 2013, p. 11-29, CARAVALE, Mario; SIGISMONDI, Francesca Laura (Org.). La facoltà giuridica romana in età liberale: prolusioni e discorsi inaugurali. Napoli: Jovene, 2014, con i saggi introduttivi rispettivamente di Paolo Grossi, Giovanni Cazzetta e Mario Caravale. 
su argomenti nodali della propria disciplina in quel momento storico, congiunto tuttavia all'aspirazione a proporsi come voce intellettuale nel dibattito più generale. Tipica è la scelta di affrontare il problema della guerra o delle colonie per l'internazionalista o per il filosofo del diritto, ${ }^{38}$ della crisi dello Stato liberale per il pubblicista, ${ }^{39}$ della legislazione speciale nel frangente del dopoguerra, ${ }^{40}$ della varietà metodologica nella scienza penalista e della necessità di superarla "scientificamente", ${ }^{41}$ o ancora di riflettere sull'itinerario storico e delle prospettive del proprio ramo disciplinare (e in proposito gli esempi sarebbero svariatissimi). Non tanto, dunque, la questione generale del metodo, quanto la sua trasposizione specifica nell'ambito coltivato; non tanto la discussione del rapporto tra visione individuale e sociale del diritto o tra diritto e altre scienze, quanto il problema del "che fare" riportato alla propria disciplina ma con risultati proposti all'esterno: positività e concretezza, dunque, nella coscienza di essere uno specialista che parla a tutti. Consentiva tutto questo la rilevata ambiguità dello strumento della prolusione, la cui funzione appare simile agli interventi svolti dal giurista nei circoli o nelle Accademie alle quali era iscritto come socio e che regolarmente venivano pubblicati. ${ }^{42}$

d) In contrasto con la fama che generalmente lo accompagna come tipo letterario divulgativo e privo di originalità, il genere enciclopedico aveva favorito l'approfondimento di molte tematiche dando impulso in definitiva alla specializzazione

38 Vi si sofferma PASSERO, Laura. Dionisio Anzilotti e la dottrina internazionalistica tra otto e novecento. Milano: Giuffrè, 2010. p. 327-418, per quanto riguarda le prolusioni o conferenze di Marinoni (1915), Buzzati (1915), Nasi (1915), Catellani (1915), dei fratelli Cimbali, Giuseppe (1914) e Eduardo (1915) e naturalmente di Anzilotti (1914), il cui testo si segnala per la spietata crudezza positivistica (la guerra come strumento al di fuori del diritto, in mano agli Stati per costruire un nuovo diritto).

39 È il tema della celeberrima prolusione pisana (1909) di Romano, ora in ROMANO, Santi. Lo stato moderno e la sua crisi. Milano: Giuffrè, 1969. p. 3-26.

40 VASSALLI, Filippo. Della legislazione di guerra e dei nuovi confini del diritto privato. Rivista del diritto commerciale e del diritto generale delle obbligazioni, Milano, v. 17, parte 1, 1919. p. 1-22, parte I (si tratta della prolusione con cui il giurista romano intraprendeva l'insegnamento a Genova). Su temi contigui, all'inizio e al termine della guerra intervenne un altro grande civilista, nella stessa tribuna apprestata da Sraffa e Vivante: FERRARA, Francesco. Influenza giuridica della guerra nei rapporti civili. Rivista del diritto commerciale e del diritto generale delle obbligazioni, Milano, v. 13, parte I, 1915. p. 25-47 e FERRARA, Francesco. Diritto di guerra e diritto di pace. Rivista del diritto commerciale e del diritto generale delle obbligazioni, Milano, v. 16, parte I, p. 682-714, 1918. p. 682-714. Per la prolusione di Ruffini (1920) v. oltre, nt. 77.*

41 ROCCO, Arturo. Il problema e il metodo della scienza del diritto penale. Rivista di diritto e procedura penale, Milano, v. 1, 1910. p. 497-521; 561-582. Sulla prolusione, nella sterminata bibliografia, v. di recente il dibattito Legittimazione e metodo della scienza penale: a cento anni dalla prolusione sassarese di Arturo Rocco.Criminalia, Annuario di scienze penalistiche, Pisa, 2010, p. 127-252 (con testi di Massimo Donini, Giovanni Fiandaca, Renzo Orlandi, Tullio Padovani, Domenico Pulitanò). Recentemente sull'autore, anche con nuovi risultati di ricerca, v. la voce di Marco Paolo Geri in Dizionario biografico degli italiani. Roma: Istituto della Enciclopedia Italiana, 2017. v. 88.

42 Gli esempi sono innumerevoli e riguardano anche giuristi meno noti e "periferici", a testimonianza di un tessuto intellettuale che si andava consolidando. Se ne trovano molti nelle voci dedicate ai vari giuristi in DBGI, cit. 
delle diverse discipline. I due repertori giuridici che iniziarono le pubblicazioni nei primi anni Ottanta sottendevano infatti una duplice finalità: il tentativo, da un lato, di raffigurare il circuito complessivo dell'ordinamento vigente del nuovo Stato quale precipitato storico della lunga tradizione culturale che aveva accomunato le genti italiche, dall'altro di articolare in forma specialistica e aggiornata le varie materie. E molte sono le voci che riflettono gli assetti giuridici nuovi assunti dalle relazioni civili in seno all'età crispinogiolittiana e le modalità specifiche della presenza dello Stato.

In questi repertori enciclopedici l'emersione della specializzazione poté realizzarsi, in primo luogo, grazie alla coralità della partecipazione all'impresa che, mentre chiudeva la plurisecolare stagione costellata di lessici e repertori partoriti con faticosa erudizione individuale, permetteva di assegnare la redazione dei lemmi a veri esperti; in secondo luogo in virtù dello spazio accordato alla redazione dei testi, apparentemente senza limiti, posto che non pochi risultano avere le dimensioni di un'ampia monografia. ${ }^{43}$

Non stupisce perciò che all'aprirsi del Novecento non solo le voci contenute nelle due raccolte, ma il genere stesso enciclopedico tendesse a specializzarsi. Tra il 1904 (ma in dispense già tre anni prima) e il 1920 uscì, sotto la direzione iniziale di Enrico Pessina, l'Enciclopedia del diritto penale italiano, formidabile panoramica del settore, comprensiva anche della procedura cui erano dedicati 6 volumi sui 20 complessivi. Un altro esperimento corale e specialistico si ebbe nell'ambito del diritto privato sotto l'egida di Vittorio Scialoja che, a partire dal 1900, promosse il Dizionario pratico di diritto privato, ${ }^{44}$ mentre nel campo pubblicistico, pure dal 1900 in volume, cominciò a vedere la luce il Primo trattato completo di diritto amministrativo italiano, ideato da Vittorio Emanuele Orlando. ${ }^{45}$

L'enumerazione potrebbe continuare. Quel che importa sottolineare è che si trattava di prove assai distanti dal genere del commentario ai codici per lo sforzo di elaborazione e per l'equilibrio con cui i singoli contributi individuali si incastonavano entro il progetto collettivo. Le discipline crescevano non come somma di opere, bensì come una rete di apporti entro un corpus, che progressivamente andava stabilendo un proprio statuto attinente alla materia (i contenuti essenziali e la partizione), al reclutamento

43 Questi stessi caratteri contribuirono a dilatare i tempi di pubblicazione (l'Enciclopedia giuridica italiana rimase incompleta a distanza di oltre 50 anni dall'esordio) e spiegano una certa descrittività che talora affiora e che diminuisce la compattezza dell'opera. Considerazioni in BIROCCHI, Italo. Enciclopedie giuridiche tra storia e valutazione scientifica. In: CONTE, Giuseppe (Org.). Evoluzione e valutazione della ricerca giuridica. Napoli: Edizioni Scientifiche Italiane, 2015a. p. 217-221.

44 L'opera cessò le pubblicazioni dopo l'ottavo tomo (alla lettera p), nel 1952, passando nel tempo sotto la direzione di Bonfante, di Roberto De Ruggiero e di Maroi.

45 Il Primo trattato apparve in fascicoli nel 1897 ed ebbe una faticosissima lavorazione (17 tomi fino alle ultime dispense del 1937). Cfr. CIANFEROTTI, Giulio. Il pensiero di V. E. Orlando e la giuspubblicistica italiana fra ottocento e novecento. Milano: Giuffrè, 1980. p. 173-189. 
dei professori (con i requisiti di accesso che avveniva ormai per cooptazione e non più per decisione ministeriale), agli strumenti e al cursus honorum (si regolarizzò un percorso che procedeva dalle Università piccole o periferiche a quelle maggiori). Il processo di autonomia disciplinare fu accompagnato dalla formazione di scuole che, legate a un metodo, tesero col tempo a darsi strumenti espressivi (per lo più riviste); ma questo apparterrà soprattutto alla storia successiva.

4. Dall'enciclopedia alla condivisione del metodo: l'asserita scientificità della scienza giuridica

Il cammino della specializzazione appare irresistibilmente tracciato, anche se non mancano le personalità - per lo più della generazione precedente, magari ancora attive negli anni Dieci del Novecento - capaci di essere protagonisti in più discipline. ${ }^{46}$ $\mathrm{Ci}$ fu, è vero, l'idea forte di una rifondazione della scienza giuridica a partire da concettualizzazioni tratte dalla romanistica, con il conseguente corollario di diffondere l'immagine del giurista "completo" educato allo studio storico e sistematico del diritto romano quale perno del rinnovamento. Ma, come si vedrà tra breve, questo orientamento non si risolse di per sé in una spinta all'attualizzazione dell'antico diritto e non mise in discussione la propensione verso gli specialismi.

Ad incidere in quest'ultima direzione, c'era, sebbene in funzione secondaria, una motivazione soggettiva, giacché ne traeva vantaggio il giurista, che aveva tendenzialmente una strada segnata e non doveva disperdere le proprie energie improvvisando alla meglio pubblicazioni sulle più svariate materie, in attesa di una problematica riuscita (i concorsi e le petizioni di nomina a un insegnamento negli anni Sessanta-Settanta sono popolati da candidati che appaiono letterati polivalenti ma non di rado anche avventurieri della penna). Tendenzialmente lo specialismo accresceva il prestigio del cattedratico perché gli conferiva un ruolo ben definito all'interno della Facoltà e della disciplina di appartenenza: radicava nella cattedra il professore, che si distingueva in quanto tale e che perciò tendeva a far diventare solo complementari le altre occupazioni svolte (a cominciare da quella, usuale, dell'avvocato). ${ }^{47}$

46 È il caso di Carlo Francesco Gabba (1835-1920), di Pasquale Fiore (1837-1914) e di Francesco Filomusi Guelfi (1842-1922), la cui autorevolezza (riconosciuta anche in campo pratico con nomine a commissioni concorsuali, oltre che sul piano scientifico con la pubblicazione dei lavori nelle diverse riviste specialistiche) si estese in materie diverse e abbastanza lontane come il civile/la filosofia/l'internazionale, per il primo, almeno l'internazionale/il civile per il secondo e il civile/la filosofia/l'enciclopedia per il terzo. Anche loro finirono comunque per essere precipuamente ascritti a una disciplina (la prima di quelle rispettivamente indicate per ciascuno).

47 Sul prestigio, assai basso, del professore rispetto all'avvocato, ancora verso la metà degli anni Ottanta, pagine gustose in COGLIOLO, Pietro. Malinconie universitarie. Firenze: Barbèra, 1887. p. 40, 62 e passim. 
Ma soprattutto la convenienza soggettiva si innestava su un processo oggettivo, indotto dal moltiplicarsi dei compiti e delle attività dello Stato che non solo si ripercuoteva nella estensione delle materie del diritto pubblico, ma anche nella torsione verso un orientamento pubblicistico di materie ed istituti tradizionalmente ricondotti ad ottiche privatistiche. Si pensi ai rapporti di lavoro, o al processo civile (sempre meno "affare dei soggetti" e attratto invece nell'orbita statuale), o ancora alla materia del diritto internazionale (pubblico), i cui cultori ben presto avevano rifiutato di procedere di regola con le categorie civilistiche. Il crescere della legislazione speciale aveva poi eroso la centralità dei codici e segnatamente del codice per antonomasia, quello civile, già considerato supremo strumento ordinante attorno a cui ruotava il sistema, e favorito il nascere di branche sempre più complesse (di volta in volta trasversali o parcellizzate: si pensi al diritto industriale, delle assicurazioni, dei trasporti).

Parallelamente in Italia era durata poco la candidatura - maturata sullo scorcio dell'Ottocento - dell'Enciclopedia giuridica come scienza formativa e coesiva dei diversi specialismi. Come ebbe a dire uno dei suoi massimi cultori, Biagio Brugi, «preme che il giovane acquisti consapevolezza del legame organico che intercede fra le varie parti costituenti oggi la giurisprudenza, che si divisero e suddivisero non per capriccio di dotti, ma per naturale legge di progresso». ${ }^{48}$ Ecco, l'Introduzione enciclopedica alle scienze giuridiche, che il ministro Coppino, proprio per questa funzione, alla metà degli anni Settanta volle anteporre alla filosofia del diritto, avrebbe dovuto costituire il raccordo complessivo tra discipline, vitali in sé ma parcellizzate e bisognose di un cemento interconnettivo. E un altro grande cultore dell'Enciclopedia, Francesco Filomusi Guelfi, espresse con nettezza l'idea che alla materia fosse da riconoscere il ruolo di "scienza delle scienze" perché nel suo precipitato storico-filosofico-dogmatico essa esprimeva i principi fondanti delle diverse branche del diritto: racchiudeva dunque un sistema ordinante capace raccogliere le sfide dello specialismo moderno e di mantenere l'unitarietà della scienza giuridica. (BIROCCHI, 2017, v. 88, p. 865). Ma nonostante l'elevato livello di diversi altri cultori della disciplina - conviene almeno ricordare anche Pasquale Del Giudice $^{49}$-, capaci di padroneggiare la dimensione storica e filosofica del diritto senza

48 Espressioni che compaiono nella prefazione alla prima edizione (1890) riprodotte nella quarta edizione di BRUGI, Biagio. Introduzione enciclopedica alle scienze giuridiche e sociali nel sistema della giurisprudenza. Milano: Società Editrice Libraria, 1907. p. VII-VIII. Il giurista aggiungeva che la materia era fondamentale per abituare il giurista in formazione a pensare e a ragionare: dunque ad avere un metodo ordinante.

49 I giuristi citati, tutti precocemente attratti dalla scienza giuridica tedesca, avevano fatto tesoro ed aggiornato lo sforzo sviluppato dalla dottrina attiva in quel secolo abbondante che separa l'opera di Pütter dalla Encyclopädie der Rechtswissenschaft curata da Franz von Holtzendorff. Di recente una panoramica fino all'età di Romagnosi è tratteggiata in PARINI VINCENTI, Sara. Un 'vecchio' noi ed un 'nuovo' loro. L'Introduzione enciclopedica allo studio del Diritto di G. D. Romagnosi. Italian Review of legal History, 
iati tra teoria e pratica, l'ipotesi che l'Enciclopedia potesse servire da collegamento tra le varie discipline durò una breve stagione e la materia si ridusse a fungere da introduzione all'apprendimento giuridico.

Conclusione storicamente comprensibile e difficilmente evitabile. L'idea che ogni materia constasse di un'ossatura basilare ridotta e potesse compendiarsi in pochi principi costanti come parte di un organismo unitario che si esprimeva con un linguaggio comune era fin troppo artificiale e illusoria: l'insegnamento enciclopedico si risolveva in una gabbia di nozioni elementari inservibili per governare l'universo giuridico e incapace di tener dietro ai suoi continui sviluppi. E tuttavia si fondava su un presupposto che germinerà in un'altra direzione e che costituì poi la base di una diversa ricomposizione dell'unità della scienza giuridica: che cioè il diritto, da un lato, si dovesse "semplificare" attraverso la sua depurazione dalla politica e dalla filosofia $o$, più ancora, da tutto il pregiuridico che lo accompagnava e che pure, mentre se ne predicava l'estraneità rispetto all'analisi giuridica, non veniva disconosciuto; e, dall'altro, che si dovesse riorganizzare attraverso la robusta presenza di una giurisprudenza capace di introspezione storica, educata all'uso delle concettualizzazioni, sensibile alle esigenze pratiche.

In tal modo l'unitarietà si sposava con lo specialismo disciplinare. Quasi emblematica, in proposito, la figura di Vittorio Scialoja: giurista "completo", presente in tante tribune diverse, protagonista nell'ambito del diritto processuale come dell'amministrativo, nelle tematiche civilistiche come nel diritto coloniale e nell'internazionale, ma romanista per vocazione, per l'uso della strumentazione specifica della materia e dei mezzi espressivi specifici che gli consentirono di organizzare precocemente una scuola. ${ }^{50} \mathrm{E}$ a riprova: il suo allievo Chiovenda nacque appunto come romanista, ma, senza rinnegare mai la sua formazione, si specializzò e divenne un (spesso si dice $i l$ ) maestro riconosciuto della scuola processualcivilista italiana.

Si può dire dunque che la comunicazione tra le materie non si stabiliva sul piano dei contenuti, bensì su quello del metodo. I giuristi reagirono alla complessità del reale accentuando l'importanza della specializzazione come strumento per governare il fenomeno giuridico, in un duplice senso: specializzazione di ciascuna disciplina e della scienza giuridica nel suo complesso, rispetto alle altre scienze sociali. ${ }^{51}$

Milano, n. 1, p. 1-16, 2015. Disponibile in: <http://irlh.unimi.it/wp-content/uploads/2017/03/SaraParini_2015_1.pdf>.

50 In questo senso v. le due eccellenti messe a punto del suo profilo intellettuale e della sua collocazione all'interno della scienza giuridica: STOLFI, Emanuele. Vittorio Scialoja. In: VV. AA. Enciclopedia italiana di scienze, lettere ed arti: il contributo italiano alla storia del pensiero. Roma: Instituto della Enciclopedia Italiana. 2012. Appendice 8: Diritto. p. 397-400 e CHIODI, Giovanni. In: BIROCCHI, Italo et al. Dizionario biografico dei giuristi italiani. Bologna: Il Mulino, 2013. v. 2, p. 1.833-1.837.

51 Tuttora freschissime le pagine di CIANFEROTTI, Giulio. Il pensiero di V. E. Orlando e la giuspubblicistica italiana fra ottocento e novecento. Milano: Giuffrè, 1980. p. 211-215, entro un quadro ricostruttivo della 
Il percorso che qui si è tratteggiato non è in contrasto con la raffigurazione usuale che, a partire dagli anni Ottanta dell'Ottocento, per la dottrina giuridica italiana vede un rivolgimento dei referenti, col declino dell'attrazione per il modello francese e con l'accoglimento dei canoni della Pandettistica. A conferma, i tanti soggiorni di perfezionamento nelle Università tedesche e i durevoli rapporti intessuti con queste, non solo da parte dei cultori del diritto romano e della storia, ${ }^{52}$ ma anche delle discipline positive e pratiche (un Fusinato tra gli internazionalisti, per esempio, o un Ruffini tra gli ecclesiasticisti, o un Asquini tra i commercialisti). Nessun dubbio che la scuola italiana si rinnovò guardando essenzialmente all'esempio tedesco, con i suoi principali capiscuola, dal menzionato Scialoja a Orlando (amministrativista e costituzionalista), da Alfredo Rocco (commercialista) a Chiovenda (processualcivilista), da Arturo Rocco (penalista) a Ranelletti (amministrativista), da Filomusi Guelfi (ormai civilista) ad Anzilotti (internazionalista); e anche coloro che, non convinti di dover seguire l'orientamento prevalente, mantennero un'attenzione viva per il legame tra diritto e sociologia (Miceli, ad esempio, o Manfredi Siotto Pintor nella pubblicistica, e addirittura due convinti positivisti come Ferri e Florian nel penale) praticarono un modus agendi comprensivo, paghi di poter comunque esprimere le proprie posizioni. ${ }^{53}$ Dal suo canto un personaggio come Brugi, che rivendicava con orgoglio di essere stato allievo di Bruns e di Gneist, non smise mai di combinare l'accostamento concettualizzante con la visione storica e l'interesse sociologico. (MASI, 2017, v. 88, cit. I, p. 342-345).

Ma è una conferma storiografica che non chiude e piuttosto apre problemi, giacché per comprendere l'articolato processo di costruzione della cultura giuridica nazionale la chiave interpretativa incentrata sul trapasso dall'influenza della scuola dell'esegesi a quella della Pandettistica si mostra insufficiente. Già l'immagine della staffetta Francia-Germania fa sorridere per la sua sommarietà e ricorda altri asseriti cambi di testimone nella precedente esperienza giuridica, opportunamente criticati dalla storiografia recente. ${ }^{54}$ Per quanto riguarda l'Ottocento, gli studi ultimi attestano che la

scuola giuridica nazionale fino all'avvento del fascismo.

52 Recentemente sui tours degli storici del diritto in Germania v. GRAVINA, Giacomo Pace. "Una cattedra nuova di materia nuova": storici del diritto in Italia dall'unità alla grande guerra. In: BIROCCHI, Italo e BRUTTI, Massimo (Org.). Storia del diritto e identità disciplinari: tradizioni e prospettive. Torino: Giappichelli, 2016. p. 53 e CIANFEROTTI, Giulio. 1914: le università italiane e la Germania. Bologna: Il Mulino, 2016. p. 92 e ss.

53 Nel volgere della sua vita accademica, sintomatico l'accenno autobiografico di FLORIAN, Eugenio. Schema di autobiografia intellettuale. In: FLORIAN, Eugenio et al. Eugenio Florian: maestro del positivismo penale: in occasione del suo commiato dall'Università. Milano: Bocca, 1940. p. 227-228.

54 È nota la metafora della fiaccola detenuta inizialmente dalla scienza giuridica tardo-medievale italiana, poi ceduta ai culti francesi, da questi alla Scuola elegante dei Paesi Bassi e infine alla Francia della Rivoluzione (la riproponeva ad esempio, LIEBMAN, Enrico Tullio. Storiografia giuridica "manipolata". Rivista di Diritto Processuale, Padova, v. 29, parte 1, 1974. p. 113, che allungava addirittura il percorso della staffetta 
simpatia per la scuola dell'esegesi era durata pochi decenni, dopo i codici napoleonici ed aveva in sostanza prevalso una cultura eclettica, ${ }^{55}$ di carattere storicistico e "civile", che aveva caratterizzato i decenni a cavallo dell'età unitaria. L'eclettismo è forse la cifra costante della cultura giuridica italiana e, per definizione, ha colori cangianti. Nell'epoca che qui interessa - con la seconda generazione postunitaria - è pieno dispiegamento di forza originale: significa piena consapevolezza che l'architettura postnapoleonica era troppo semplicistica (il giudizio e il termine è di Santi Romano), ${ }^{56}$ ma anche che il guardare alla Germania non poteva sfociare nel ricalco di un altro modello già dato. ${ }^{57}$ Insistentemente - nella rivista di Ascoli o in quella di Sraffa e Vivante, nelle prolusioni o nell'uso corrente - si parlava di "scuola italiana", con particolare riferimento alle singole discipline di ambito pubblicistico (specialmente quelle giovani: la processualcivilistica come la internazionalistica, per la quale, al tempo di Anzilotti, si rinnovava l'espressione già in uso per l'antica scuola manciniana, peraltro, ai suoi tempi, rimasta un unicum). Con la consueta efficacia, in poche densissime pagine, interveniva Scialoja. (SCIALOJA, 1911b, v. 9, parte 1, p. 941-948). Persino un giurista atipico e col gusto della propria distinzione come Francesco Carnelutti, gettando uno sguardo sulla formazione scientifica della disciplina alla quale dalla metà degli anni Dieci dedicò le sue maggiori cure, parlò di "scuola italiana del diritto processuale" che per la costruzione della dogmatica si era valsa, sì, dei concetti tedeschi, ma solo come «scalino da puntarci il piede». ${ }^{58}$

Si comparava e le letture si ibridavano, in relazione a una riflessione che passava per una conoscenza storica e concerneva il funzionamento delle istituzioni e la legislazione da riformare o da impiantare ex novo: come scandiva il grande allievo di

segnalando anche il passaggio dalla Francia alla Germania): ne ha fatto giustizia OSLER, Douglas J. The myth of European legal history. Rechtshistorisches Journal, Frankfurt am Main, v. 16, p. 393-410, 1997. p. 393-410.

55 L'espressione è stata introdotta e a più riprese arricchita di considerazioni da LACCHÈ, Luigi. I giuristi italiani e il risorgimento: Una proposta per rileggere la questione della cultura giuridica nazionale e delle "scuole" a partire dal canone eclettico. Rivista italiana per le scienze giuridiche, Napoli, v. 4, p. 317-361, 2013. Numerosi profili dei giuristi ottocenteschi, in DBGI, dimostrano che, con espressioni particolarmente vive nella cultura giuridica meridionale, il predominio dell'esegesi fu tutt'altro che indiscusso e durevole: il mondo del diritto non fu certo popolato solo da commentari codicistici.

56 ROMANO, Santi. Lo stato moderno e la sua crisi. Milano: Giuffrè, 1969. p. 13. E quasi negli stessi anni in cui fu pronunciata la prolusione di Romano, il suo maestro Orlando, impegnato a sua volta in una prolusione alla Sapienza romana, riflettendo sulle teorie realistiche dello Stato offriva tra l'altro spunti interessanti sui concetti di originalità ed eclettismo applicati alla scienza giuridica ORLANDO, Vittorio Emanuele. Lo stato e la realtà: discorso inaugurale del Prof. Vittorio Emanuele Orlando. Annuario dell'anno scolastico 1910911. Regia Università degli studi di Roma, Roma, p. 5-31, 1911. p. 18-20.

57 Tra le tante testimonianze v. CALAMANDREI, Piero. Gli studi di diritto processuale in Italia nell'ultimo trentennio (I ediz. 1941). In: Scritti sul processo civile. Padova: Cedam, 1947a. v. 5. p. 115

58 CARNELUTTI, Francesco. Scuola italiana del processo. Rivista di Diritto Processuale, Padova, v. 2, parte 1, p. 233-247, 1947, oltre che nel titolo, a p. 239 e 241 (per la citazione). Cfr. anche LIEBMAN, Enrico Tullio. Storiografia giuridica "manipolata”. Rivista di Diritto Processuale, Padova, v. 29, parte 1, 1974. p. 117. 
Orlando nella prolusione pisana, «costruire e non distruggere: è questo, più che altro, il compito che deve proporsi, rispetto all'ordinamento politico, l'evolversi dell'attuale vita sociale e, quando avrà costruito, probabilmente i nuovi edifici non contrasteranno con la solida e severa architettura dello Stato moderno, ma poggeranno sulle stesse sue basi e ne costituiranno parti integranti» (ROMANO, 1969, p. 20). Perciò si è parlato di cantiere. Il rinnovamento riguardava sia l'aspetto sostanziale, cioè i materiali sui quali il diritto era chiamato a dare le sue regole, sia quello formale, ovvero il metodo per tradurre in diritto l'esigenza pratico-sociologica.

Sotto il primo profilo si insisteva sulla missione del giurista ad ascoltare la natura delle cose (die Natur der Sache o, marxianamente, die Natur der Dinge), che parla al di fuori della gabbia degli schemi: si trattava di recepire l'esistenza e la vita delle aggregazioni sociali (partiti, leghe, associazioni cattoliche) e del mondo del lavoro (sindacati e società professionali, addirittura nell'ordine della magistratura, come era avvenuto nel 1909 con la fondazione dell'Associazione generale fra i magistrati d'Italia), (MENICONI, 2012, p. 102 e 106) ma anche di prestare attenzione alle innovazioni indotte nelle relazioni intersoggettive dalla tecnica. Non stupisce che i giuristi più sensibili fossero i commercialisti e i pubblicisti. Forte è la ventata nuova che proveniva dal periodico di Vivante e di Sraffa e poi dalla capacità di iniziativa di Alfredo Rocco, ormai insediato a Padova. L'apertura all'Europa non era una novità, essendo già stata praticata da Mancini e da Vidari, entrambi de resto internazionalisti nelle origini e dalla spiccata vocazione comparatistica. Ora però l'orizzonte europeo era sempre aperto: la Rivista del diritto commerciale, che usciva in due poderose parti ogni anno con le sue sezioni, si occupava dei grandi istituti, ospitata saggi metodologici, dibatteva la legislazione e la giurisprudenza e conteneva una rassegna sistematica delle opere straniere. ${ }^{59}$ Nel libro del centenario del code Napoléon, lo specialista francese aveva disegnato la parabola ottocentesca di un commerciale attirato dalla forza razionalizzatrice del codice civile, fino a constatare che, per la sete di unità degli ordinamenti moderni, era inevitabile giungere alla presente realtà tedesca, in cui la branca commerciale era diventata un satellite del civile. ${ }^{60}$ La commercialistica italiana, paradossalmente favorita dal "ritardo" della

$59 \quad$ Per l'insieme di tali caratteri la Rivista di Sraffa e Vivante sarà il modello al quale guardò l'ex commercialista Carnelutti, allorché, prima a Lessona (1918), poi a Chiovenda (1923), propose di fondare la Rivista di procedura civile (questo il nome originario da lui indicato e poi corretto su suggerimento di Chiovenda nel passaggio alla pubblicazione nel 1924: v. CIPRIANI, Franco. Scritti in onore dei patres. Milano: Giuffrè, 2006, spec. p. 277-280.

60 THALLER, Edmond Eugène. De l'attraction exercée par le code civil et par ses méthodes sur le droit commercial. In: SOREL, Albert. Le code civil 1804-1904: livre du centenaire. Paris: Rousseau, 1904. p. 225-243, spec. 240 e 243) (ristampa in un solo volume, Paris: Dalloz, 2004). Sul giurista francese, professore di diritto commerciale a Lione e Parigi, v. la voce di HALPÉRIN, Jean-Louis. In: ARABEYRE, Patrick; HALPÉRIN, Jean-Louis; KRYNEN, Jacques. Dictionnaire historique des juristes français XII ${ }^{e}-X X^{e}$ siècle. 
civilistica, cominciò a parlare all'Europa in termini rovesciati: l'intera società civile era pensabile essenzialmente come un insieme di operazioni di scambio, con i suoi soggetti individuali o aggregati (le imprese). ${ }^{61}$

I pubblicisti non erano da meno. La prassi non si accontentava di definire i limiti al potere, ma poneva l'esigenza della partecipazione democratica alla gestione della cosa pubblica; così non era più un tabù prospettare il problema della rappresentanza tenendo conto - di nuovo questo suggeriva con forza l'analisi del reale - delle differenziazioni all'interno dei processi produttivi e del mondo intellettuale, che cresceva in modo frastagliato con lo sviluppo dell'istruzione e degli apparati degli uffici; e la guerra, ovviamente, aveva ulteriormente accentuato la questione dichiarando irreversibile la crisi della rappresentanza liberale. ${ }^{62}$ Tra gli internazionalisti nessuno più sosteneva che il principio di nazionalità fosse un criterio giuridico, addirittura il perno del diritto internazionale sia pubblico che privato, secondo la lezione di Mancini. E tuttavia la nazione era tutt'altro che morta: considerata dato sociologico, se ne prendeva le mosse per tutelarla - da soggetto del diritto internazionale diventava oggetto delle sue cure, ad esempio con la legislazione di favore per gli irredenti (FEDOZZI, 1915, spec. p. 34-36) e per assicurare gli sbocchi coloniali connaturati alla sua esistenza, come insistentemente si sosteneva. ${ }^{63}$

\footnotetext{
Paris: PUF, 2015. p. 960.
}

${ }^{61}$ Ne fornisce una impressionante testimonianza la costruzione della persona giuridica come entità patrimoniale autonoma, formulata da un commercialista che preferì non salire mai la cattedra come Gustavo Bonelli (1853-1926): v. ora STELLA RICHTER, Mario Jr. Persona giuridica e società. In: . Gustavo Bonelli: un giurista in Banca d'Italia (no prelo). p. 107-124 (di imminente pubblicazione e letto in anteprima per la cortesia dell'autore).

62 Come recita, nell'immensa bibliografia, il titolo di TRIFONE, Gian Paolo. Il diritto al cospetto della politica: Miceli, Rossi, Siotto Pintòr e la crisi della rappresentanza liberale. Napoli: Edizioni Scientifiche Italiane, 2010. Tra i protagonisti del tempo basti segnalare RUFFINI, Francesco. Guerra e riforme costituzionali. Suffragio universale, principio maggioritario, elezione proporzionale, rappresentanza organica. Annuario della R. Universià di Torino, 1919-1920, Torino, 1920, tanto lucido e realistico quanto animato da un impegno civile volto alla speranza (si tratta della rielaborazione della prolusione letta il 24 novembre 1919 a Torino).

${ }^{63}$ I giuristi, e non solo gli internazionalisti, accompagnano con i loro interventi l'impresa libica (1911): CIANFEROTTI, Giulio. Giuristi e mondo accademico di fronte all'impresa di Tripoli. Milano: Giuffrè, 1984. Il diritto coloniale nasce come un diritto di specialità, codificando diseguaglianze e gerarchie e dunque contro il significato originario del principio di nazionalità, consolidato verso la metà dell'Ottocento (Mancini, Mamiani), quale diritto all'autodeterminazione dei popoli. Come è noto, nella retorica che si afferma a cavallo tra i due secoli il principio di nazionalità non vale per i popoli tribali: nei loro confronti l'opera di colonizzazione sarebbe l'esercizio del diritto/dovere delle nazioni più forti di portare la civilizzazione. Nella sterminata letteratura basti segnalare il panorama tracciato in Quaderni fiorentini, Milano, 33/34, 2004/2005, la sintesi di MARTONE, Luciano. Il diritto coloniale. In: CAPPELLINI, Paolo et. al. (Org.). Il contributo italiano alla storia del pensiero. Diritto. Roma: Istituto della Enciclopedia Italiana, 2012. p. 542-549 e, recentemente, DE NAPOLI, Olindo. Tra progresso del diritto e "turn to empire": il percorso dei giuristi italiani di fronte al colonialismo da Mancini all'età giolittiana. Italia Contemporanea, n. 274, p. 7-41, 2014. 
Nel diritto processuale civile si assiste a un vivacissimo dibattito che spesso si presentava come discussione sulla penetrazione del germanesimo o quale contrasto tra indirizzo pragmatico e modello romano, ma che in realtà riguardava la definizione di giurisdizione, la natura del processo, il ruolo delle parti e del giudice. È una discussione che, per la forte personalità degli attori (si parla di Mortara e di Lessona, di Chiovenda fino ai più giovani Carnelutti, Redenti e Calamandrei, che negli anni Dieci si affacciarono nella disciplina) e per i mezzi che avevano a disposizione - di volta in volta, le aule accademiche e quelle del Parlamento, le tribune degli avvocati e gli uffici governativi, le opere scientifiche e le commissioni di riforma legislativa, i progetti di codificazione - ha talvolta indotto la storiografia a focalizzare l'attenzione verso le rivalità individuali o di scuola, o, all'opposto, a tagliar corto sui contrasti semplificando l'interpretazione come se si trattasse dei contrasti tipici del passaggio dall'esegesi all'impostazione sistematica cara alla Pandettistica. Ma quella filosofia che è sempre presente nella scienza processualistica era legata alla prassi: non solo i ritardi, le "trappole" e i costi dell'agire in giudizio, ovvero le disfunzioni dell'ordinamento, ma anche il problema delle procedure speciali e del ruolo del giudice rispetto alle parti. ${ }^{64} \mathrm{E}$ la direttrice pubblicistica del processo, l'idea dell'astrattezza dell'azione rispetto al diritto sostanziale e molte delle soluzioni proposte (non delle ideologie sottostanti) erano comuni ai protagonisti della disciplina, che nell' intensa palestra di interventi andavano ripensando le regole sul rapporto tra giustizia e Stato di diritto. ${ }^{65}$

Lo stesso vale per i penalisti, che sin dagli anni Ottanta avevano portato l'attenzione del diritto criminale verso i luoghi in cui i delitti si commettevano e tra le persone dei delinquenti, analizzando le periferie e i manicomi, le carceri e i crani e i nervi dei devianti. Gli eccessi dello sperimentalismo furono moderati e però l'abito mentale che ne era alla base fu assimilato e ripreso, come si vedrà tra breve, all'interno della scuola che proprio all'inizio del secondo decennio del Novecento verrà ribattezzata tecnicogiuridica. Più avanti, in uno schizzo autobiografico, Eugenio Florian, uno dei maggiori esponenti della scuola positiva ricorderà che inizialmente i seguaci e lui stesso dovettero

\footnotetext{
64 Alla vigilia della fine della prima guerra mondiale Scialoja, il teorico che nelle aule della Sapienza romana aveva disegnato una prospettiva storico-teorica (sul corso di lezioni tenuto nel 1893-94 - Esercizio e difesa dei diritti: procedura civile romana - ed edito in prima edizione nel $1894 \mathrm{v}$. CARRATTA, Antonio. Vittorio Scialoja ed il processo civile. Bullettino dell'Istituto di Diritto Romano "Vittorio Scialoja", Milano, v. 1, Quarta Serie, 2011. p. 103-134, tracciava il quadro vivo dei problemi nell'ambito del processo SCIALOJA, Vittorio. I problemi dello Stato italiano dopo la guerra. Bologna: Zanichelli, 1918. p. 286-287. È noto che il suo allievo Chiovenda di lì a poco produrrà un progetto complessivo, primo di una sequenza che vide impegnati, spesso in alternativa, tutti i maestri della disciplina fino all'esito del codice varato dal guardasigilli Grandi nel 1940.

${ }_{65}$ Per il periodo qui esaminato, il ruolo della scienza processualcivilistica nel farsi carico dei problemi generali della giustizia è messo in evidenza da TARUFFO, Michele. La giustizia civile in Italia dal '700 a oggi. Bologna: Il Mulino, 1980. p. 185.
} 
persino faticare a respingere le accuse di non essere "giuristi", salvo sapersi cimentare in monografie dedicate alle categorie o specie di delitti (FLORIAN, 1940, p. 228).

I dati del reale, che un tempo erano richiesti alla collaborazione dello statistico, dell'economista o del sociologo, ${ }^{66}$ erano assunti direttamente dal giurista in virtù della propria specializzazione su un campo determinato, ovviamente filtrati col suo metodo. Entra qui in considerazione il secondo aspetto della sua attività, attinente alla forma, esclusivamente giuridica, secondo la quale dichiarava di voler operare. Congiunto all'aspetto sostanziale, questo atteggiamento connota il giurista nuovo. Confinate nel pregiuridico le suggestioni, pure ben presenti, provenienti dalla politica, dalla filosofia e dal sociale, il metodo doveva essere rigorosamente tecnico nell'elaborazione e nell'uso dei concetti e sistematico nella loro disposizione. Si trattava finalmente di un metodo scientifico, essendo compendiati i due requisiti della specializzazione e della unitarietà della scienza giuridica.

Si registrò una comunanza di metodo, dunque, tanto che, semplificando molto, i capiscuola dei vari comparti disciplinari poterono per lo più richiamarsi alla Pandettistica, salvo fiere e comprensibili eccezioni, ${ }^{67}$ ma senza che ciò significasse, già lo si è detto, un porsi a ricalco della scienza ottocentesca tedesca. ${ }^{68} \mathrm{E}$ nel complesso il senso degli sforzi fu verso la positivizzazione del diritto, conseguenza della depurazione operata attraverso il metodo: una positivizzazione che si predicava potesse avvenire solo sotto l'egida dello Stato, motore e armatura del sistema che la scienza giuridica andava allestendo. Nella disciplina internazionalistica Anzilotti è certamente l'eponimo di un tale esito. ${ }^{69} \mathrm{Ma}$ in campo amministrativistico lo stesso vale per il sistema di Ranelletti e in

66 Emblematica la figura di Angelo Messedaglia, chiamato alla Facoltà di Giurisprudenza della Sapienza romana subito dopo lo spostamento della capitale e per un trentennio ascoltatissimo professore di Filosofia della statistica, statistica e economia politica v. DE RIGO, Maria Cristina. I processi verbali della Facoltà Giuridica Romana: 1870-1900. Roma: Viella, 2002. p. 745 e ss; sulla sua personalità GIOIA, Vitantonio; NOTO, Sergio (Org.). Angelo Messedaglia e il suo tempo: atti del convegno. Macerata: EUM, 2011.

67 È il caso, per esempio, di Enrico Ferri, che mai avrebbe accettato quell'etichetta e che tuttavia, mentre vide in parte recepito il suo accostamento alla materia penalistica da parte degli antichi avversari, attenuò in qualche misura la distanza con i sostenitori del metodo tecnico, accettando anche forme di collaborazione. Ne sono segni l'incarico di codificazione della materia da parte di Mortara (allora ministro) nel 1919, che sfociò nel progetto Ferri, e la partecipazione alla commissione chiamata a discutere il testo del futuro codice Rocco (1927) COLAO, Floriana. Le scuole penalistiche. In: CAPPELLINI, Paolo et. al. (Org.). Il contributo italiano alla storia del pensiero. Diritto. Roma: Istituto della Enciclopedia Italiana, 2012. p. 851-852.

${ }_{68}$ Solo per riferirsi al problema di rintracciare le suggestioni da cui nacque l'opera di uno degli eponimi del decennio qui illustrato, Santi Romano: plausibilmente le si sono trovate in Gierke, ma pure per qualche aspetto nella nouvelle vague francese operante a cavallo tra i due secoli (Geny, Duguit). Sembra però appropriato ritenere che il giurista siciliano non fosse legato ad alcun modello, nemmeno a quello del suo maestro Orlando.

69 GAJA, Giorgio. Positivism and dualism in Dionisio Anzilotti. European Journal of International Law, v. 3, n. 1, p. 123-138, 1992; PASSERO, Laura. Dionisio Anzilotti e la dottrina internazionalistica tra otto e novecento. Milano: Giuffrè, 2010; SALERNO, Francesco. L'affermazione del positivismo giuridico nella scuola internazionalista italiana: il ruolo di Anzilotti e Perassi. Rivista di Diritto Internazionale, Milano, v. 
quello costituzionale per la teoria degli ordinamenti di Santi Romano, la cui apertura pluralistica era comunque posta - almeno nella prima versione dell'opera - sotto l'egida di uno Stato da rafforzare nella sua superiorità come sintesi dell'interesse collettivo. Persino in ambito privatistico si fece sentire lo sfondo statuale della teorizzazione dottrinale con la proposta di collocare il diritto di famiglia nell'orbita pubblicistica: non tanto un soggetto di diritto, quanto un istituto espressivo di un complesso di diritti e obblighi che lo Stato indefettibilmente riconosceva e tutelava senza margini dispositivi per le parti. ${ }^{70}$

Una prima conclusione sembra pacifica e riguarda il rapporto dialettico tra la dottrina e l'azione dello Stato. Nessuno spazio per quella freie Rechtsfindung che si risolveva in freie Rechtswissenschaft predicata da Ehrlich, così come in generale non ebbero seguito in Italia gli orientamenti della scuola del diritto libero. ${ }^{71}$

\section{A riprova: i percorsi giovanili di sei giovani studiosi che vanno in cattedra}

Si può osservare tutto questo restando fondamentalmente nello stesso decennio di riferimento guardando questa volta ai giovanissimi giuristi che in quel periodo erano agli esordi, avendo vent'anni o poco più. L'impegno nell'officina è frenetico e

95, 2012. L'affermazione del positivismo giuridico nella scuola internazionalista italiana: il ruolo di Anzilotti e Perassi, SALERNO, Francesco. L'affermazione del positivismo giuridico nella scuola internazionalista italiana: il ruolo di Anzilotti e Perassi. Rivista di Diritto Internazionale, Milano, v. 95, 2012. spec. p. 41-50; ALLAND, Denis. Anzilotti et le droit international public: un essai. Paris: Pedone, 2013, (quest'ultimo discute però, in chiave problematica, alcuni aspetti del pensiero di Anzilotti, che mostrerebbero il riaffiorare di prospettive giusnaturalistiche nel giurista toscano. Si sa del resto che Anzilotti non smise mai di revisionare il suo sistema, a cominciare dal problema della formazione della "volontà collettiva" [Vereinbarung] degli Stati per cui si avvicinò, per il tramite di Perassi, al principio kelseniano della Grundnorm).

70 Si allude alla teorizzazione, peraltro contrastata, di CICU, Antonio. Il diritto di famiglia: teoria generale. Roma: Athenaeum, 1914.

71 EHRLICH, Eugen. Freie rechtsfindung und freie rechtswissenschaft: soziologie und jurisprudenz. Leipzig: Hirschfeld, 1903. Critici furono SCIALOJA, Vittorio. Diritto pratico e diritto teorico. Rivista del diritto commerciale e del diritto generale delle obbligazioni, Milano, v. 9, parte 1, p. 941-948, 1911b. p. 947-948 e poi i giovani formatisi negli anni Dieci: oltre a Giuseppe Maggiore (cfr. MARINI, Gaetano. Giuseppe Maggiore. L'interferenza di filosofia e diritto. Napoli: Edizioni Scientifiche Italiane, [1983]. p. 63-65), MOSSA, Lorenzo. Il diritto del lavoro. Sassari: Stamperia della Libreria italiana e straniera, 1923. p. 10-11, che è la prolusione al corso sassarese del 1922-23, BETTI, Emilio. Metodica e didattica del diritto secondo Ernst Zitelmann. Rivista Internazionale di Filosofia del Diritto, Roma, p. 17-18, 1925, ora in BETTI, Emilio. Diritto, metodo, ermeneutica: scritti scelti. Milano: Giuffrè, 1991a. p. 17-18, CALAMANDREI, Piero. Il giudice e lo storico. In: CALAMANDREI, Piero. Scritti sul processo civile. Padova: CEDAM, v. 5, 1947c. p. 44. (I ediz. 1939). È un tema non molto approfondito nella storiografia italiana, ma si ritrovano diversi spunti (ad esempio a proposito del pensiero del giovane Cesarini Sforza) nel vasto saggio sull'interpretazione nella dottrina tra la fine dell'Ottocento e la prima metà del Novecento di COSTA, Pietro. L'interpretazione della legge: François Gény e la cultura giuridica italiana fra ottocento e novecento. Quaderni Fiorentini: per la storia del pensiero giuridico moderno, Milano, v. 20, p. 367-495, 1991. p. 367495. In generale LARENZ, Karl. Storia del metodo nella scienza giuridica. Milano: Giuffrè, 1966. p. 82-87 e WIEACKER, Franz. Storia del diritto privato moderno: con particolare riguardo alla Germania. Milano: Giuffrè, 1980. v. 2. p. 336-339. 
inquieto: diversissimi tra loro, personaggi come Vassalli, Mossa, Asquini, Calamandrei, Betti e Jemolo maturano esperienze di grande spessore, ognuno a modo proprio. Il più anziano di tutti, Vassalli (1885-1955), educato al diritto romano da Moriani, fa le prime prove a Perugia e Cagliari per passare, sotto la guerra, sotto la guida di Scialoja, allora ministro, che lo impiega come uomo fidato nella commissione addetta studio della legislazione del dopoguerra; promosso ordinario dallo stesso Scialoja (1918) e chiamato nello medesimo anno a Genova, lascerà per sempre la cattedra romanistica per quella civilistica, unendo alla sensibilità storica uno spirito pratico che ne fece tra l'altro un grande avvocato. Mossa (1886-1957) opera girovago tra Genova, dove si laurea con Manara (1907), la sua Sassari, e Torino dove diventa assistente di Sraffa, che lo introduce nel salotto della sua rivista con l'incarico di fare attenzione alla letteratura tedesca, nel momento in cui si costruiva la proposta del Wirtschaftsrecht e si sviluppava la riflessione sulla legislazione di guerra. Il giovane sardo non andò in guerra e in quegli anni si incontrò con un altro esentato dal conflitto, Emilio Betti, nella piccola Università di Camerino ove entrambi ebbero il loro primo incarico, prima di ottenere - giovanissimi - la vincita all'ordinariato. Il romanista marchigiano (1890-1968) era allievo di Segrè, ma in sostanza era un autodidatta capace di assorbire genialmente dagli incontri con gli uomini e con i libri. Già con due lauree, con un posto di funzionario di biblioteca, un possesso superbo del tedesco e con le prime ricerche pubblicate, lo scoppio della guerra lo sorprese mentre svolgeva un soggiorno di studio nella Friburgo tedesca. Dopo alcuni rovesci concorsuali (ma era appena venticinquenne), su consiglio di Segrè andò nel 1916 a consultare Scialoja e ne ebbe un rabbuffo per la soverchia dimensione erudita delle sue ricerche, insieme alla raccomandazione di riportare il diritto, anche nello studio dell' antichità, alla prassi: ${ }^{72}$ ne nascerà l'amore per le esercitazioni, l'interesse a sperimentarsi come consulente e addirittura a insegnare la procedura civile. ${ }^{73}$ Elementi apparentemente variegati, eppure tutti confluenti in quella dogmatica pratica a cui poi Betti attese per il resto dell'attività. Dal suo canto, Asquini (1889-1972), nazionalista convinto, fece la guerra in Libia e a Rodi, si laureò nel 1912 e, già professore a Urbino, combatté come ufficiale nel primo conflitto mondiale. Sostenuto da Rocco, dopo la laurea aveva studiato un anno a Monaco; alla fine del decennio, appena trentenne, era già ordinario in uno dei luoghi politicamente più caldi

72 In questa indicazione Scialoja era del tutto coerente SCIALOJA, Vittorio. Diritto pratico e diritto teorico. Rivista del diritto commerciale e del diritto generale delle obbligazioni, Milano, v. 9, parte 1, p. 941948,1911 b. In una nota iniziale della rivista che ospitava il saggio, i due direttori - Sraffa e Vivante - lo definivano «un coraggioso programma di ideale riforma per tutti noi».

73 La testimonianza del giurista è nella prefazione di BETTI, Emilio. Efficacia delle sentenze determinative in tema di legati d'alimenti. In: Diritto, metodo, ermeneutica: scritti scelti. Milano: Giuffrè, $1991 \mathrm{~b}$. p. 7; vi si sofferma MURA, Eloisa. Emilio Betti, oltre lo specchio della memoria. In: BETTI, Emilio. Notazioni autobiografiche. [Assago]: Cedam, 2014. p. XXIII. La prima edizione dell'autobiografia di Betti è del 1953. 
di allora, Trieste, ideale trampolino di lancio per il commercialista che voleva fare anche politica. ${ }^{74}$ Calamandrei (1889-1956), figlio d'arte, studiò con una delle personalità più forti della processualcivilistica italiana del tempo, quel Carlo Lessona che per altra via rispetto a Chiovenda portò il soffio della sensibilità storica nel rinnovamento della materia e che lasciò indelebile all'allievo, insieme all'affezione per la dimensione sociale del diritto. Laureatosi a Pisa nel 1912, interventista democratico convinto, vinse precocemente il concorso per la cattedra, segnalandosi prestissimo, nonostante gli anni di guerra, tra i protagonisti di quella dottrina che nella disciplina ebbe fama di eccellenza in Europa. Jemolo (1891-1981), infine: negli anni Dieci l'allievo di Ruffini aveva ereditato da questi (e da Federico Patetta, altro suo professore per il quale ebbe attrazione) l'amore per la storia, insieme al rigore per il metodo. Dopo la laurea (1911) si sperimentò come funzionario ministeriale, ma acquisì giovanissimo la libera docenza (1916), militò attivamente nel movimento contro la guerra pur avendo avuto simpatie nazionaliste, brigando poi per essere richiamato al fronte - lo richiedeva il suo onore per fugare l'eventuale sospetto che potesse essere considerato un imboscato -, fu fatto prigioniero e restituito solo dopo un anno alla vita civile, subito inviato come esperto giuridico presso la Commissione per le riparazioni a Vienna. Anche lui, però, nel 1920 era già in cattedra. ${ }^{75}$

Percorsi eterogenei, indubbiamente, che a prima vista paiono accomunati solo dal raggiungimento dell'ordinariato in giovane età. Ma i profili dei personaggi ora evocati, che appartengono alla terza generazione dei giuristi postunitari (nati attorno al 1890), ribadiscono i caratteri che si sono sopra individuati come linea di tendenza e che appunto si ritrovano stabilizzati negli allievi allora appena emergenti. Conviene ripercorrerli.

a) Lo specialismo. Vassalli iniziò la carriera come romanista e non rinnegò mai la sua formazione, che gli serviva del resto come retroterra per comprendere e

74 Le biografie parlano di insegnamenti a Sassari e Messina, dopo la guerra, ma si tratta rispettivamente dell'Università che bandì il concorso (vinto da Asquini) e di quella che lo chiamò, senza che l'allievo del potentissimo Rocco vi calcasse aula universitaria, temporeggiando nell'attesa della sistemazione presso l'Istituto Superiore di Commercio della città giuliana, in cui fu presto nominato preside. Sull'ordinamento italiano a Trento e Trieste nel dopoguerra v. CAPUZZO, Ester. Dall'amministrazione militare all'ordinamento italiano: Trento e Trieste tra il 1919 e il 1922. Clio, Napoli, v. 24, n. 1, 1988. p. 37-81.

75 Inutile indicare una bibliografia sui sei notissimi giuristi. Le informazioni principali si ritrovano nel DBGI, cit., ad nomen e sono state integrate attraverso i testi autobiografici disponibili ASQUINI, Alberto. $X X X$ Tricesimo. Roma-Paris-Bruxelles: Editioni Anastatike e Istituto di Skriptura, [1995]; BETTI, Emilio. Notazioni autobiografiche. Padova: Cedam, 2014; JEMOLO, Arturo Carlo. Anni di prova. Firenze: Passigli, 1991. [prima edizione: 1969], CALAMANDREI, Piero. Zona di guerra: lettere, scritti e discorsi (19151924). Roma-Bari: Laterza, 2006 e lo spoglio dei rispettivi fascicoli personali conservati in Archivio Centrale dello Stato, Ministero della Istruzione pubblica, Direzione generale istruzione superiore: rispettivamente, III versamento, b. 473, fasc. Vassalli Filippo; III versamento, b. 330, fasc. Mossa Salvatore Lorenzo; III versamento, b. 22, fasc. Asquini Alberto; III versamento, b. 53, fasc. Betti Emilio; *...versamento, b. *, fasc. Calamandrei Piero; III versamento, b. 255, fasc. Jemolo Carlo Arturo. 
comparare e dunque per operare nel presente; dalla prima guerra mondiale in poi, come avvocato, legislatore e professore fu comunque un civilista di spicco assoluto. Il più atipico è Betti, per il quale può sorgere qualche dubbio, posto che ebbe anche la cattedra civilistica (a Roma, dal 1948 al 1954) e tenne corsi di Procedura civile, Diritto internazionale, Teoria del diritto. Ma iniziò, terminò e visse come romanista e solo per sei anni lasciò tale cattedra, unicamente perché la chiamata alla Sapienza non poteva avvenire sulla sua materia. Soprattutto, al di là di questa contabilità, Betti fu uno specialista per i canoni che lui stesso elaborò nella sua concezione della dogmatica: per lui il plesso diritto civile-romano era un tutt'uno perché permetteva di analizzare i materiali romanistici secondo la dogmatica del diritto presente. Quanto alla procedura - si sa che ebbe allievi di gran nome anche in questo settore -, era affascinato dal nesso tra il diritto sostanziale e il sistema delle actiones e la considerava la via per il riscontro effettuale, per l'applicazione degli istituti nel mondo reale. Insomma, in sé «un giurista integrale, che aborrì la specializzazione», come è stato convincentemente detto, (MURA, 2014, p. $\mathrm{XX}$ ) per l'originale commistione tra gli interessi storico-filosofici coltivati in gioventù e costantemente amati, e la dimensione pratica che sempre accolse, eppure anche un giurista che dovette fare i conti con l'ormai consolidato specialismo disciplinare delle Università.

b) La tensione pratica. È un carattere che ci si aspetta per i due commercialisti Mossa ed Asquini, educati a riflettere sui materiali sostanziali dell'organizzazione industriale e degli scambi, per il civilista Vassalli e il processualcivilista Calamandrei, nelle cui opere davvero si registra una connessione costante tra cattedra e foro, attività di studio e redazione di leggi. Di Betti si è già detto e lui stesso ci ha lasciato la testimonianza del suo pensiero sull'attività di consulenza, intrapresa sin dai tempi di Macerata e Parma e poi coltivata anche a Milano, ${ }^{76}$ ma non gli fu da meno l'ecclesiasticista Jemolo, che nelle due principali città in cui a lungo operò (Bologna e Roma), collegò stabilmente l'attività ex cathedra con il lavoro da avvocato. ${ }^{77}$

76 MURA, Eloisa. Emilio Betti, oltre lo specchio della memoria. In: BETTI, Emilio. Notazioni autobiografiche. [Assago]: Cedam, 2014. p. XXIX e BETTI, Emilio. Notazioni autobiografiche. Padova: Cedam, 2014. p. 21 e 29. Vengono in mente altri romanisti, attivi in quegli stessi anni Dieci, eccellenti consulenti: nella generazione precedente, Bonfante, che lavorò anche con Sraffa, e Carlo Fadda, tanto acuto annotatore del Diritto delle Pandette di Windscheid, quanto rinomato nell'attività forense nella pur affollata postazione napoletana; poi Scialoja, che presiedette il Consiglio dell'ordine degli avvocati di Roma (1913-26) e poi il Consiglio Superiore forense dopo la riforma fascista dell'avvocatura BIROCCHI, Italo. Il giurista intellettuale e il regime. In: BIROCCHI, Italo; LOSCHIAVO, Luca (Org.). I giuristi e il fascino del regime (1918-1925). Roma: Roma Tre-Press, 2015b. p. 9-61. p. 38, nt. 114; e infine, quasi coetaneo di Betti, Filippo Vassalli, che pose il suo studio a Roma qualche anno dopo la fine della grande guerra.

77 Oltre che nella sua autobiografia JEMOLO, Arturo Carlo. Anni di prova. Firenze: Passigli, 1991. p. 177, ne parla a più riprese nel carteggio con un altro grande consulente, l'amico Giorgio Falco, al quale chiese spesso aiuto: v. ad esempio JEMOLO, Arturo Carlo. Lettere a Mario Falco, t. 2 (1928-1943), a cura di Maria Vismara Missiroli. Milano: Giuffrè, 2009. v. 89 (Per la storia del pensiero giuridico moderno). p. 105, 137, 344. 
c) L'appartenenza a (grandi) scuole. Scialoja, Sraffa e Rocco, Ruffini e Segrè (con il beneplacito ancora di Scialoja), Lessona (con Chiovenda consenziente) sono i numi tutelari ai quali non conviene pensare semplicemente per spiegare le fortune accademiche dei sei giovani giuristi. ${ }^{78}$ Il caposcuola si occupava sì dei concorsi, ma era anche un organizzatore che avviava alla ricerca, teneva i contatti con i colleghi, promuoveva canali espressivi, interveniva con la propria autorevolezza sul metodo e sui temi d'attualità; e correlativamente ci si incanalava negli studi e si era membri della comunità disciplinare attraverso le scuole, che tendevano a governare gli accessi (il concorso si risolveva in una cooptazione) e a stabilire un cursus honorum attraverso le chiamate e i trasferimenti nelle sedi. Prodotti eminentemente storici nella vita delle discipline, le scuole attraversavano negli anni Dieci il periodo della loro costruzione e ascesa.

d) Il rinnovamento dei temi. È un'altra coniugazione dell'attenzione per la pratica. Fuoriuscire dal modello della società codificata implicava dedicarsi alle situazioni dell'attualità e, col declino del modello individuale astratto, ai soggetti concreti e perciò diversificati onde governarli col diritto. L'inclinazione pubblicistica fu il carattere comune della cultura giuridica a cui i sei futuri maestri appartennero, fosse essa coniugata a proposito del processo, della causa nel contratto, della funzione della proprietà o dell'organizzazione dell'impresa e del lavoro. Il giurista era attento al sociale - s'intende: anche qui in tutta concretezza, secondo gli assetti di forza e i meccanismi espressivi che vi si affermavano - ed era chiamato a rispondere intessendo la rete degli istituti giuridici e predisponendo possibili soluzioni normative. In tal modo la crescita del ruolo del giurista non entrava in conflitto, anzi ribadiva la ricetta positivistica essendo suo compito operare il passaggio dalla confusa situazione pregiuridica delle cose alla indiscutibilità, se non alla purezza, del diritto posto dall'autorità. ${ }^{79}$ La si può definire un'opera di mediazione tecnica, alla quale naturalmente non era estranea la dimensione sostanziale.

e) Il prestigio della carriera universitaria. Forte dello specialismo e di un impegno appositamente dedicato alla ricerca e all'insegnamento, il titolare di cattedra vedeva crescere la considerazione sociale nei suoi confronti, mentre andava declinando quella verso l'avvocatura. Lo si registra indirettamente dal numero di giuristi nominati senatori, pur non essendoci una apposita categoria di professori di diritto tra le 21 enucleate dallo Statuto albertino per indirizzare le scelte del monarca; non pochi sono i giuristi che, negli anni che qui interessano, ebbero una responsabilità quali ministri o primi ministri, da Fusinato a Gianturco, da Orlando a Salandra, da Scialoja a Mortara, da Schanzer a Ruffini.

\footnotetext{
$78 \quad$ Anche qui con la parziale eccezione di Betti.

79 Facile, in relazione ai sei giovani studiosi di cui si è parlato, dimostrare questo modo di operare per i due commercialisti. Non la stessa conclusione si ricava a prima vista dal tema affrontato da Jemolo per la sua libera docenza, dedicato a un problema storico: ma il tormentato allievo di Ruffini rifletteva lì sul nodo attualissimo delle diverse confessioni entro lo Stato.
} 
Non stupisce che la carriera universitaria fosse preferita a quella dell'alta burocrazia e magari del giudice (è il caso, tra i giovani giuristi di cui abbiamo parlato, di Jemolo e di Betti, ma, tra gli altri, di Vittorio Scialoja, Carlo Lessona, Solmi, Fedozzi, Ghirardini, Maggiore nonché, qualche anno dopo, di Cesarini Sforza, Mortati, Bertola e Jannacone). ${ }^{80}$

f) Il giurista come intellettuale. Le biografie dei giuristi riportano innumerevoli testimonianze di partecipazione alla vita pubblica, con la presenza nei salotti o nei circoli di élite o con la pubblicazione di studi o tesi complessivamente rivolte all'opinione pubblica; ed è davvero singolare che la notissima polemica intercorsa tra Bonfante e Croce (1917) a lungo sia stata considerata quasi come una manifestazione isolata e abnorme proprio per la "strana" apparizione di un giurista nel dibattito intellettuale. ${ }^{81}$ Nel prossimo paragrafo si accennerà ad alcuni episodi particolarmente rilevanti della loro presenza pubblica, ma conviene rimarcarlo già adesso. È una novità che pone interrogativi, ma iI fatto è che anche i giuristi apparentemente chiusi nel recinto accademico, come ad esempio Mossa, si sentivano immersi nel sociale e protagonisti diretti nella politica, consapevoli di avere qualcosa da dire essendo, appunto, giuristi.

Non è un caso che tra $\mathrm{i}$ giovani studiosi menzionati ci fosse una propensione all'autobiografia. ${ }^{82} \mathrm{Si}$ dirà che era un genere coltivato nella Germania weimariana, all'apogeo dello splendore della scienza giuridica prima dell'avvento del nazionalsocialismo: conscia dell'alta funzione svolta nel comparto sociale, nell'apposita sezione giuridica della collana Die Wissenschaft der Gegenwart in Selbstdarstellungen pubblicò un insieme di profili che rispondevano a un questionario sull'esperienza dei singoli giuristi a partire dalla formazione iniziale. ${ }^{83}$ Ma il caso italiano è assai diverso e non sembra merce d'importazione. Si tratta infatti di espressioni personalissime, a volte

80 In contrario si potrebbero citare i casi di Lucchini e di Mortara, che passarono dai ranghi dell'Università a quelli della magistratura. Ma, a parte motivazioni di tipo personale, furono utilizzate norme particolari e i due giuristi vennero assunti nella magistratura con un grado elevato; per Mortara, poi, si tratta di un doppio scambio: dall'iniziale occupazione in magistratura passò alla cattedra e di nuovo alla magistratura, per finire come avvocato dopo la forzosa decadenza della carica in Cassazione decretata dal governo mussoliniano (1923).

${ }^{81}$ Conviene ricordare che il giovane Bonfante, nel 1895, aveva già sottolineato che il giurista poteva contribuire all'innovazione progressiva del diritto in qualità di "consigliere" del Principe, assai più che tramite l'interpretazione v. COSTA, Pietro. L'interpretazione della legge: François Gény e la cultura giuridica italiana fra ottocento e novecento. Quaderni Fiorentini: per la storia del pensiero giuridico moderno, Milano, v. 20, p. 367-495, 1991. p. 412.

82 Mossa non pubblicò una autobiografia, ma i ricorsi autobiografici sono frequenti nella sua opera. Neanche Vassalli diede alle stampe alcuna autobiografia in senso proprio, ma la sua autodifesa in occasione del procedimento di epurazione VASSALLI, Filippo. In tema di "epurazione" (deduzioni alla commissione ministeriale). Roma: Bardi, 1945, nonché molti degli scritti editi dopo il 1943 contengono numerosi riferimenti alla propria esperienza di "legislatore" e di professore.

${ }^{83}$ I profili erano 24, raccolti in tre volumi PLANITZ, Hans (Org.). Die rechtswissenschaft der gegenwart in selbstdarstellungen. Leipzig: Meiner, [1923-1925]. v. 1-3. La consapevolezza del ruolo della scienza giuridica è espressa dal curatore nel Vorwort (v. 1, p. V-VII). 
drammatiche, esterne al magistero accademico, che manifestano a posteriori la coscienza di una collocazione specifica nella società civile: non un mestiere utile per la sussistenza, e nemmeno sciolto indistintamente nella vaga categoria del letterato, bensì con una funzione sociale, pratico-educativa, senza contraddizione col tecnicismo del metodo e del linguaggio.

6. Scientificità come neutralità. il giurista si fa intellettuale pratico e si presta come legislatore

Tiriamo le fila. L'affermazione generalizzata di un metodo depuratore e tecnico sembrerebbe proporci un quadro in cui tutto si esprime e si racchiude nelle costruzioni impersonali della scienza giuridica, con i suoi strumenti operativi e metodologici. Ma in fin dei conti si è parlato di giuristi, perché a pensare, costruire ed agire sono inevitabilmente gli uomini: ed è proprio attraverso questa angolazione che agevolmente si coglie la storicità della scienza giuridica, le cui forme hanno un senso e vivono solo in quanto riferite all'uomo sociale.

Il giurista di cui abbiamo parlato può essere considerato secondo una duplice ordine di appartenenze, tra loro interrelate: quale soggetto attivo in seno alla scienza giuridica (di solito, distinto entro una disciplina) e, insieme ai suoi compagni di lavoro, come partecipe di spicco alla sezione intellettuale della prima società di massa quale fu, in Italia, quella dell'età giolittiana. Emerge, insomma, pur nella singolarità dei percorsi personali, la figura del giurista-intellettuale ed è un fatto nuovo, tipico del Novecento e però dai caratteri continuamente cangianti nel corso del secolo.

È noto che il sostantivo "intellettuale" compare appena poco prima degli anni di cui qui ci si è occupati, in sostituzione di "letterato" e inizialmente con un significato ironico nella società disomogenea del primo Novecento. ${ }^{84}$ L'intellettuale svolge il proprio ruolo nel confronto con i valori incarnati nelle istituzioni e nella cultura, formula analisi e giudizi che travalicano il proprio corpo di appartenenza e che perciò in qualche modo guardano al "tutto". ${ }^{85}$ Nell'ovvia storicità del suo ruolo, a maggior ragione

${ }_{84}$ TURI, Gabriele. Lo stato educatore: politica e intellettuali nell'Italia fascista. Roma-Bari: Laterza, 2002. p. 7; BONGIOVANNI, Bruno. Intellettuali. In: BONGIOVANNI, Bruno; TRANFAGLIA, Nicola (Org.). Dizionario storico dell'Italia unita. Roma-Bari: Laterza, 2007. p. 462-463.

85 «In Italia la figura del moderno intellettuale e la consapevolezza di un suo ruolo protagonistico si vengono precisando nell'età giolittiana quando, mentre inizia a svilupparsi una società di massa che richiede il ricorso a strumenti di comunicazione e di omogeneizzazione nazionale, il carattere ancora arretrato del paese - per la debole alfabetizzazione e la carenza di moderne strutture associative - enfatizza il ruolo di mediazione degli uomini di cultura. In questa fase si ha, in forme autonome dalle organizzazioni politiche, una politicizzazione degli intellettuali»: TURI, Gabriele. Lo stato educatore: politica e intellettuali nell'Italia fascista. Roma-Bari: Laterza, 2002. p. 13. 
è storica la collocazione del giurista, che si contrae o si amplia a fisarmonica, insieme alla propria autonomia, sempre relativa, tanto più che è storico e perciò relativo il diritto che maneggia: i margini di libertà e indipendenza entro cui la sua funzione concretamente opera si riflettono immediatamente sia nella cultura delle istituzioni, sia nella formazione dell'opinione pubblica che, sostegno indispensabile delle società di massa, ha una importanza particolare per quanto attiene al consenso sulle linee fondamentali dell'ordinamento. ${ }^{86}$

In questo generalissimo quadro si colloca quanto osservato nelle pagine precedenti. Innanzi tutto va ricordato il distinto protagonismo dei giuristi, con singolare capacità di afferrare i temi del momento e di trattarli sia ex professo, sia sul piano divulgativo, con proposte e schieramenti aperti (la guerra, la questione coloniale, la rappresentanza politica, l'irredentismo, il problema dell'istruzione, l'organizzazione del mondo del lavoro e dell'impresa). È un protagonismo evidente in chi era impegnato personalmente nella vita politica (un Alfredo Rocco e un Arrigo Solmi, ad esempio, entrambi nazionalisti), ma non meno palese in tanti altri giuristi, legati a circoli e associazioni o magari semplicemente maestri che parlavano ex cathedra (Del Vecchio o Santi Romano, Bonfante o Venezian, Jemolo o Anzilotti, Leicht e Filomusi Guelfi: l'elenco sarebbe lunghissimo). Si nota una consapevolezza di ruolo, che si legge in controluce nelle testimonianze dei giovanissimi futuri giuristi: in Betti, ad esempio, il quale nel 1916 prende la penna e intavola un rapporto scientifico-intellettuale con Croce che si protrarrà con simpatia per tutti gli anni Venti; ${ }^{87} \mathrm{o}$ in Maggiore, che nello stesso torno d'anni stringe relazioni con Gentile e polemizza con Croce; ${ }^{88} \mathrm{o}$ in Asquini, che, di ritorno dal soggiorno di studio in Germania, viene invitato dal suo maestro, Alfredo Rocco, a profondere il suo impegno nelle riviste politico-culturali; (ASQUINI, [1995], p. 18) o ancora in Jemolo, che tra il 1914 e il 1915 intreccia le prime relazioni intellettuali - tra gli altri, con Croce, "nume tutelare" - nel circolo Italia nostra impegnato contro l'intervento in guerra e poi,

86 Sulla formazione/informazione dell'opinione pubblica, mobilissima nel tempo, v. ora STOLZI, Irene. Le inchieste parlamentari. Un profilo storico-giuridico (Italia, 1861-1900). Milano: Giuffrè, 2015. v. 107. p. 39-55.

87 Il fatto è noto (ne parla lo stesso BETTI, Emilio. Notazioni autobiografiche. Padova: Cedam, 2014. p. 17, e la lettera è stata anche pubblicata in tempi recenti da NITSCH, Carlo. Il giudice e la legge. Consolidamento e crisi di un paradigma nella cultura giuridica italiana del primo novecento. Milano: Giuffrè, 2012. v. 96. (Per la storia pensiero giuridico moderno). p. 305-306.

88 La testimonianza del futuro filosofo e penalista vicino alle posizioni del nazismo e razzista di punta, è contenuta nella sua autobiografia: MAGGIORE, Giuseppe. Vita di nessuno: note autobiografiche. Cuneo: Ghibaudo, 1954. p. 154 e ss. Sulla polemica con Croce, a proposito del rapporto tra diritto e morale, cfr. MARINI, Gaetano. Giuseppe Maggiore. L'interferenza di filosofia e diritto. Napoli: Edizioni Scientifiche Italiane, [1983]. p. 43-54. 
al termine del conflitto, nel cenacolo riunito attorno a Bonaiuti (uno dei 12 professori che rifiutarono il giuramento al fascismo). ${ }^{89}$

In secondo luogo l'accreditarsi del ruolo autonomo del giurista attraverso due vie compresenti. Da un lato, con l'affermazione del metodo tecnico-giuridico o dogmatico, depurato dagli aspetti extra- o pregiuridici (politici, sociologici), di cui perciò si asseriva la neutralità, con la conseguente pretesa di scientificità del discorso giuridico e dell'indipendenza del giurista. Dall'altro, con la diffusione dello specialismo, che comportava il dominio monopolistico della propria area, con tendenziale indispensabilità dell'opera del giurista in virtù della sua insostituibilità (elaborazione, interpretazione, applicazione delle norme).

Facile ovviamente rilevare che il tecnicismo della scienza giuridica e il suo specialismo non significavano assenza di ideologia o indifferenza rispetto ai rapporti di forza e agli schieramenti. ${ }^{90}$ Talvolta, del resto, quando le circostanze invitavano a denudare il discorso, nella difesa del diritto positivo si arrivava a riconoscere che quest'ultimo (tutto: quello internazionale direttamente, quello interno per vie mediate) era e non poteva non essere l'ordinamento del più forte, secondando in ciò il "naturale progresso dell'umanità": con la conseguenza che compito scientifico del giurista era coglierlo, dargli forma e sistemazione e applicarlo. ${ }^{91}$

Senza contraddizioni, l'età del positivismo scientifico - ricco e complesso, perché variegata e multiforme era la società che esso regolava - si celebrava con l'apporto determinante e consapevole della scienza giuridica. Si può parlare di una propensione del giurista a cooperare col legislatore, con un'occupazione che per alcuni diventa pressoché stabile. Certo si tratta di un impegno di élite, che riguarda comunque centinaia di professori, magistrati, alti burocrati. Viene in considerazione innanzi tutto l'attività

89 JEMOLO, Arturo Carlo. Anni di prova. Firenze: Passigli, 1991. p. 132-133; cfr. FANTAPPIÈ, Carlo. Arturo Carlo Jemolo: riforma religiosa e laicità dello Stato. Bréscia: Morcelliana, 2011. p. 11-57.

90 Nitidissima la coscienza in Calamandrei, allorché metteva in evidenza che discussioni come quella sulla natura dell'azione e sulla pubblicizzazione del processo erano connesse con opzioni o visuali politiche: «La polemica ha dunque uno sfondo essenzialmente politico; questo avviene, ed è bene che avvenga, anche se non sempre i giuristi se ne accorgono, in ogni elaborazione sistematica degli istituti giuridici: nell'interpretare i quali i tecnici, anche quando credono di essere fedeli alla lettera delle disposizioni positive, non possono esimersi dall'esaminarli contro luce al chiarore di certe fondamentali tendenze». CALAMANDREI, Piero. Il giudice e lo storico. In: CALAMANDREI, Piero. Scritti sul processo civile. Padova: CEDAM, v. 5, 1947c. La relatività del concetto di azione (I ediz. 1939), in CALAMANDREI, Piero. Scritti sul processo civile. Padova: CEDAM, v. 5, 1947d. p. 3. Formulate per la dottrina processualcivilistica ma certamente generalizzabili.

91 Non si tratta dell'affermazione di un giurista di seconda fila, bensì di uno dei momenti forti della prolusione tenuta da Anzilotti all'Università di Roma inaugurando l'anno accademico 1914-15 ANZILOTTI, Dionisio. Il concetto moderno dello Stato e il diritto internazionale. In: Scritti di diritto internazionale pubblico. Padova: Cedam, 1956. v. 1. Il concetto moderno dello Stato e il diritto internazionale (1915), in ANZILOTTI, Dionisio. Il concetto moderno dello Stato e il diritto internazionale. In: . Scritti di diritto internazionale pubblico. Padova: Cedam, 1956. v. 1. p. 629. La prima edizione è del 1915 . 
nelle commissioni che, a più riprese ma quasi ininterrottamente, furono insediate per il rifacimento dei codici (e il decennio qui preso prevalentemente in considerazione vide anche la promulgazione del codice di procedura penale, che nel 1913 sostituì quello del 1865) o di parti significative di essi (in campo civile, commerciale, procedurale: obbligazioni, assicurazioni, processo sommario ecc.); già questo è un dato importante, perché una ripresa su vasta scala dell'opera di codificazione non deriva solo da impulsi della società politica ma segnala - savignyanamente - la coscienza e la preparazione della scienza giuridica, specialmente quando questa non opera secondo modelli dati. Non meno importante fu poi il lavorio a cui i giuristi furono chiamati per la legislazione speciale, sia nelle materie di nuovo conio (si pensi al diritto coloniale), sia nei settori più mobili del vivere civile (come l'ambito commerciale), sia per governare le situazioni di emergenza (come la guerra e il dopoguerra). Qui affiorò compiutamente l'importanza del profilo specialistico del giurista, insieme alla capacità di considerare sistematicamente i singoli problemi.

Vittorio Scialoja è forse il prototipo di questa figura di giurista legislatore, non solo perché, da ministro, mise in piedi la mastodontica commissione per la legislazione del dopoguerra, ma perché impersona in una sintesi forse unica l'uomo di scienza, il pratico, il politico, pur restando uomo di scuola. ${ }^{2}$ Un suo allievo acquisito, Filippo Vassalli, a tutti noto come maestro a Genova, Torino e Roma nonché grande avvocato, alla caduta del fascismo dichiarerà di aver svolto prevalentemente il "mestiere" di legislatore nell'ultimo quarto di secolo, a partire, appunto, dall'impegno in quella commissione per la legislazione del dopoguerra; ${ }^{93}$ e non esiterà a dedicare specificamente

92 Una testimonianza impressionante della dimensione politica (in senso lato) del suo operato è dato dalla succosissima paginetta pubblicata nel 1916. Il grande capofila dei germanisti italiani, traduttore del System savignyano, invitava a ricostituire, a partire da un rinnovato rapporto con la Francia, quel diritto comune che era stato «strumento potente di civiltà in Europa, e che si ruppe per necessità, ma non senza danno, nel grande rinnovamento delle nazioni che si iniziò nel secolo decimottavo». SCIALOJA, Vittorio. Per un'alleanza legislativa fra gli Stati dell'Intesa. Nuova Antologia, Firenze, v. 181, fascicolo 1057, p. 451452, febbr. 1916. Serie 6: lucidissima, nel testo, la coscienza della forza esercitata a suo tempo dal modello codificatorio francese e della "perfezione" insita nel recente BGB tedesco, come pure la necessità di dar corso scientificamente alle istanze di modernizzazione provenienti dal mondo commerciale e civile. Si sa che il controverso progetto di codificazione delle obbligazioni italo-francese, prodotto sotto l'egida di Scialoja, sarà il frutto di queste idee. Dati essenziali sulla Commissione per il dopoguerra (istituita con decr. luog. 21 marzo 1918, ma il cui nucleo essenziale raccolto attorno a Scialoja cominciò a operare già nell'anno precedente) sono in FURGIUELE, Giovanni. La "Rivista di diritto civile" dal 1909 al 1931. Quaderni Fiorentini: per la storia del pensiero giuridico moderno, Milano, v. 16, p. 519-630, 1987. p. 591592 nt. 283 e in CIPRIANI, Franco. Scritti in onore dei patres. Milano: Giuffrè, 2006. p. 58-59.

93 VASSALLI, Filippo. Motivi e caratteri della codificazione civile. In: VASSALLI, Filippo. Scritti giuridici. Milano: Giuffrè, 1960. v. 3, n. 2. Motivi e caratteri della codificazione civile (ediz. originale: 1947, che rielaborava un testo pubblicato nel 1942), ora in VASSALLI, Filippo. Motivi e caratteri della codificazione civile. In: VASSALLI, Filippo. Scritti giuridici. Milano: Giuffrè, 1960. v. 3, n. 2. p. 605-606. 
un saggio a La missione del giurista nella elaborazione delle leggi. ${ }^{94}$ Non meno rilevante è la funzione di "legislatore" di Ludovico Mortara (1855-1937), tutt'altro che un esegeta, secondo una fama tuttora non spenta per la sua contrapposizione con Chiovenda, e piuttosto un "clinico" per la capacità di unire la teoria con la prassi: 95 il maestro che domina oltre un trentennio la disciplina processualcivilistica italiana - da avvocato, da scrittore fecondo, da direttore della Giurisprudenza italiana, da professore universitario, da capo di gabinetto (di Orlando), da guardasigilli, da presidente di commissioni per la riforma della legislazione - fu infatti ispiratore diretto o estensore conclamato di numerosi testi normativi, a cominciare dalla riforma del processo sommario del 1901. ${ }^{96}$ L'impegno "legislativo" di Calamandrei e di Redenti, seppur più breve ma intenso e decisivo negli anni Trenta nella stessa disciplina processualcivilistica, e di Asquini, protagonista nella legislazione per l'intero ventennio fascista, va nella stessa direzione.

Non è solo una ricostruzione retrospettiva, compiuta dalla storiografia o elaborata dal ricordo dei protagonisti. Salendo sulla cattedra torinese, nel 1913 Angelo Sraffa lanciò un vero e proprio appello all'impegno del giurista verso la produzione giuridica, sulla base di una analisi tanto sintetica quanto precisa e realistica: ${ }^{97}$ specificamente riferita al settore commerciale, nel pensiero dell'autore essa poteva estendersi in larga misura all'intero comparto giuridico, sia perché l'attività di industria, scambio delle merci e finanza era il nucleo dominante della vita civile, sia perché il metodo della scienza giuridica era sostanzialmente omogeneo nelle varie branche del diritto (in proposito Sraffa si richiamava alle considerazioni di Alfredo Rocco). L'efficacissimo quadro era costruito con tre protagonisti. Da un lato il tumultuoso evolversi della società civile, che rinnovava continuamente le tecniche, rimodellava i rapporti e suggeriva o imponeva esigenze inedite, senza che una autoregolamentazione fosse possibile, a meno che non si classificasse come tale quella imposta dal più forte. ${ }^{98} \mathrm{Da}$ un altro, lo Stato, ormai protagonista nell'attività

94 Il saggio deriva dalla relazione presentata al Congresso internazionale di diritto privato (Roma 1950), ora in VASSALLI, Filippo. Motivi e caratteri della codificazione civile. In: VASSALLI, Filippo. Scritti giuridici. Milano: Giuffrè, 1960. v. 3, n. 2. p. 737-751.

95 Così lo definisce CARNELUTTI, Francesco. Scuola italiana del processo. Rivista di Diritto Processuale, Padova, v. 2, parte 1, p. 233-247, 1947. p. 245-246.

96 Sul suo impegno per la riforma della legislazione v. CIPRIANI, Franco. Scritti in onore dei patres. Milano: Giuffrè, 2006. p. 103, 110-112, 122.

97 Sotto vari aspetti riferimenti alla prolusione si leggono in STOLZI, Irene. L'ordine corporativo: poteri organizzati e organizzazione del potere nella riflessione giuridica dell'Italia fascista. Milano: Giuffrè, 2007. v. 71. (Per la storia pensiero giuridico moderno). p. 226, CHIODI, Giovanni. Introduzione. In:

(Org.). La giustizia contrattuale: itinerari della giurisprudenza italiana tra otto e novecento. Milano: $\overline{\text { Giuffrè, }}$ 2009. p. XIII e più diffusamente MONTI, Annamaria. Angelo Sraffa. Un 'antiteorico' del diritto. Milano: Egea, 2011. p. 169-176.

98 In particolare Sraffa, certo non isolato, smantellava la retorica in tema di usi, come fonte equitativa dei rapporti: proprio perché la pratica non è neutra, bensì antagonistica, gli usi riflettevano semplicemente gli interessi del contraente più forte SRAFFA, Angelo. La riforma della legislazione commerciale e la funzione 
imprenditoriale e dunque in una duplice e pericolosa veste di legislatore e di produttore di norme per se stesso; ed era illusoria l'idea che la rappresentanza politica popolare potesse fungere da contrappeso e controllo, poiché la tendenza era a riversare sul Governo i poteri di elaborazione della legislazione «a contenuto prevalentemente giuridico», ovvero, come pare di capire, sui temi dal profilo altamente tecnico (SRAFFA, 1913, p. 1.020). Da un terzo lato la scienza giuridica, ben versata nel proprio campo tradizionale dell'interpretazione; e tuttavia questa attività mostrava ormai i propri limiti, rigirandosi sempre più sterilmente su se stessa. Realisticamente per Sraffa l'avvenire non poteva non essere riposto nella legislazione; ma occorreva impedire che si procedesse verso una sorta di amministrativizzazione della sfera del diritto - e in particolare di quella commerciale, che doveva essere espressione dei privati - . Da qui il compito a cui era chiamata la scienza giuridica: contribuire direttamente alla produzione legislativa. Con le sue parole: «l'intervento continuo e sistematico della tecnica più raffinata e più obbiettiva dei giuristi nella preparazione dei nuovi istituti può costituire un efficace freno alle esagerazioni. alle tendenze burocratizzatrici e quindi, in sostanza, antidemocratiche dell'attuale socialismo di Stato». (SRAFFA, 1913, p. 1.021)..$^{99}$

L'appello denota singolare consapevolezza del ruolo intellettuale del giurista. Lontano dalle fumisterie metafisiche e coraggioso, lui che si sentiva eminentemente votato alla pratica, nel porre sin dal titolo della prolusione il problema della funzione del giurista, Sraffa chiamava a una missione ardua eppure tutta addentro al ruolo della scienza giuridica: «Difficile, è certo, questo compito: esso richiede l'indagine sulla realtà del fenomeno sociale; la determinazione delle esigenze che esso pone al diritto; la visione sintetica dei vari interessi contrastanti e la loro composizione in nome dell'interesse generale; la conoscenza perfetta del diritto vigente per determinare in qual forma giuridica debba il nuovo bisogno essere soddisfatto; il ricollegamento delle norme nuove alle vecchie; la formulazione tecnicamente precisa della norma nuova, in modo da dominarne l'adattamento al sistema». (SRAFFA, 1913, p. 1.022). ${ }^{100}$

Lo storico riconosce facilmente lo storicismo savignyano (del resto espressamente richiamato) e l'impronta della Pandettistica nel richiamo alla funzione tecnico-sistematica della scienza giuridica quale interprete di un sociale da rendere diritto vigente, senza che questo retroterra determinasse sottomissioni culturali; sa pure quel che è avvenuto nel dopoguerra col fascismo. L'appello di Sraffa può essere colto anche come un grido di allarme, purtroppo rimasto inascoltato. Rapita dall'ossessione

dei giuristi. Rivista del diritto commerciale e del diritto generale delle obbligazioni, Milano, v. 11, parte prima, 1913. p. 1.018.

99 Il corsivo è di Sraffa.

100 Il corsivo è ancora dell' autore. 
dell'ordine e magari illusa di contribuire a un orizzonte di modernità, salvo qualche eccezione la scienza giuridica vide nell'incontro tra politica e specialismi e, in particolare, nella impetuosa crescita delle funzioni di mediazione tra Stato e società e nel processo di riorganizzazione degli apparati un terreno su cui affermarsi; (TURI, 2002, p. 18-19 e 76) preferì, complessivamente, acquietarsi di fronte al potere, comprimendo la propria funzione intellettuale fino a subordinarla alla dittatura.

Ma questa è la storia successiva, su cui restano indelebili le parole amare e sconfortate, oltre che autocritiche, di uno dei più grandi giuristi-intellettuali del Novecento italiano (JEMOLO, 1991, p. 150 e ss., spec. p. 166).

São Paulo, agosto de 2016.

\section{Referências}

ALLAND, Denis. Anzilotti et le droit international public: un essai. Paris: Pedone, 2013.

ANZILOTTI, Dionisio. Il concetto moderno dello Stato e il diritto internazionale. In: Scritti di diritto internazionale pubblico. Padova: Cedam, 1956. v. 1.

ARABEYRE, Patrick, HALPÉRIN, Jean-Louis, KRYNEN, Jacques. Dictionnaire historique des juristes français: XII $-\mathrm{XX}^{\mathrm{e}}$ siècle. Paris: PUF, 2015.

ASQUINI, Alberto. XXX Tricesimo. Roma-Paris-Bruxelles: Editioni Anastatike e Istituto di Skriptura, [1995].

BETTI, Emilio. Diritto, metodo, ermeneutica: scritti scelti. Milano: Giuffrè, 1991a.

BETTI, Emilio. Efficacia delle sentenze determinative in tema di legati d'alimenti. In:

Diritto, metodo, ermeneutica: scritti scelti. Milano: Giuffrè, 1991b. p. 7.

BETTI, Emilio. Metodica e didattica del diritto secondo Ernst Zitelmann. Rivista Internazionale di Filosofia del Diritto, Roma, p. 17-18, 1925.

BETTI, Emilio. Notazioni autobiografiche. Padova: Cedam, 2014.

BIROCCHI, Italo. Enciclopedie giuridiche tra storia e valutazione scientifica. In: CONTE, Giuseppe (Org.). Evoluzione e valutazione della ricerca giuridica. Napoli: Edizioni Scientifiche Italiane, 2015a.

BIROCCHI, Italo. Filomusi Guelfi Francesco. In: VV. AA. Dizionario biografico degli italiani. Roma: Istituto della Enciclopedia Italiana, 2017. v. 88.

BIROCCHI, Italo. Il giurista intellettuale e il regime. In: BIROCCHI, Italo; LOSCHIAVO, Luca (Org.). I giuristi e il fascino del regime (1918-1925). Roma: Roma Tre-Press, 2015b. p. 9-61. 
BONGIOVANNI, Bruno. Intellettuali. In: BONGIOVANNI, Bruno; TRANFAGLIA, Nicola (Org.). Dizionario storico dell'Italia unita. Roma-Bari: Laterza, 2007.

BRACCIA, Roberta. Le strade ferrate: il silenzio dei codici unitari e le parole degli avvocati. In: BORSACCHI, Stefano; PENE VIDARI, Gian Savino (Org.). Avvocati protagonisti e rinnovatori del primo diritto unitario: storia dell'avvocatura in Italia. Bologna: Il Mulino, 2014.

BRUGI, Biagio. I fasti aurei del diritto romano: studi preliminari. Pisa: Tipografia Vannucchi, 1879. BRUGI, Biagio. Introduzione enciclopedica alle scienze giuridiche e sociali nel sistema della giurisprudenza. Milano: Società Editrice Libraria, 1907.

CALAMANDREI, Piero. Gli studi di diritto processuale in Italia nell'ultimo trentennio (I ediz. 1941). In: Scritti sul processo civile. Padova: Cedam, 1947a. v. 5.

CALAMANDREI, Piero. Il giudice e lo storico. In: CALAMANDREI, Piero. Scritti sul processo civile. Padova: CEDAM, v. 5, 1947c. p. 44.

CALAMANDREI, Piero. La relatività del concetto di azione. In: Studi sul processo civile.

Padova: Cedam, 1947b. v. 5, p. 1-26.

CALAMANDREI, Piero. Scritti sul processo civile. Padova: CEDAM, v. 5, 1947d. p. 123. Formulate per la dottrina processualcivilistica ma certamente generalizzabili.

CALAMANDREI, Piero. Zona di guerra: lettere, scritti e discorsi (1915-1924). Roma-Bari: Laterza, 2006.

CAPUZZO, Ester. Dall'amministrazione militare all'ordinamento italiano: Trento e Trieste tra il 1919 e il 1922. Clio, Napoli, v. 24, n. 1, 1988.

CARAVALE, Mario; SIGISMONDI, Francesca Laura (Org.). La facoltà giuridica romana in età liberale: prolusioni e discorsi inaugurali. Napoli: Jovene, 2014.

CARNAZZAAMARI, Giuseppe. Elementi di diritto internazionale. Catania: Crispo e Russo, 18661874. $2 \mathrm{v}$.

CARNELUTTI, Francesco. Scuola italiana del processo. Rivista di Diritto Processuale, Padova, v. 2, parte 1, p. 233-247, 1947.

CARRATTA, Antonio. Vittorio Scialoja ed il processo civile. Bullettino dell'Istituto di Diritto Romano "Vittorio Scialoja”, Milano, v. 1, Quarta Serie, 2011.

CASSESE, Sabino. Lo Stato "stupenda creazione del diritto" e "vero principio di vita", nei primi anni della Rivista di diritto pubblico (1909-1911). Quaderni Fiorentini: per la storia del pensiero giuridico moderno, Milano, v. 16, p. 501-518, 1987.

CAZZETTA, Giovanni. Il lavoro. In: CAPPELLINI, Paolo et. al. (Org.). Il contributo italiano alla storia del pensiero. Diritto. Roma: Istituto della Enciclopedia Italiana, 2012. 
CAZZETTA, Giovanni. Prolusioni, prelezioni, discorsi: l'identità nazionale nella retorica dei giuristi. In: (Org.). Retoriche dei giuristi e costruzione dell'identità nazionale. Bologna: Il Mulino, 2013, p. 11-29. p. 24.

CHAMBOST, Anne-Sophie (Org.). Histoire des manuels de droit. Une histoire de la littérature juridique comme forme du discours universitaire. Paris: Lextenso LGDJ, 2014a.

CHAMBOST, Anne-Sophie. Premiers Jalons pour une histoire des manuels de droit. In: CHAMBOST, Anne-Sophie (Org.). Histoire des manuels de droit. Une histoire de la littérature juridique comme forme du discours universitaire. Paris: Lextenso LGDJ, 2014b. p. 25-32.

CHIODI, Giovanni. Introduzione. In: . (Org.). La giustizia contrattuale: itinerari della giurisprudenza italiana tra otto e novecento. Milano: Giuffrè, 2009.

CIANFEROTTI, Giulio. 1914: le università italiane e la Germania. Bologna: Il Mulino, 2016.

CIANFEROTTI, Giulio. Giuristi e mondo accademico di fronte all'impresa di Tripoli. Milano: Giuffrè, 1984.

CIANFEROTTI, Giulio. Il pensiero di V. E. Orlando e la giuspubblicistica italiana fra ottocento e novecento. Milano: Giuffrè, 1980.

CICU, Antonio. Il diritto di famiglia: teoria generale. Roma: Athenaeum, 1914.

CIPRIANI, Franco. Scritti in onore dei patres. Milano: Giuffrè, 2006.

COGLIOLO, Pietro. Malinconie universitarie. Firenze: Barbèra, 1887.

COLAO, Floriana. Ferri Enrico. In: BIROCCHI, Italo, et al. (Org.). Dizionario biografico dei giuristi italiani (XII-XX secolo). Bologna: Il Mulino, 2013. v. 2.

COLAO, Floriana. Le scuole penalistiche. In: CAPPELLINI, Paolo et. al. (Org.). Il contributo italiano alla storia del pensiero. Diritto. Roma: Istituto della Enciclopedia Italiana, 2012.

COSTA, Pietro. L'interpretazione della legge: François Gény e la cultura giuridica italiana fra ottocento e novecento. Quaderni Fiorentini: per la storia del pensiero giuridico moderno, Milano, v. 20, p. 367-495, 1991.

DE NAPOLI, Olindo. Tra progresso del diritto e "turn to empire": il percorso dei giuristi italiani di fronte al colonialismo da Mancini all'età giolittiana. Italia Contemporanea, n. 274, p. 7-41, 2014.

DE RIGO, Maria Cristina. I processi verbali della Facoltà Giuridica Romana: 1870-1900. Roma: Viella, 2002.

DENTI, Vittorio; TARUFFO, Michele. La rivista di diritto processuale civile. Quaderni Fiorentini: per la storia del pensiero giuridico moderno, Milano, v. 16, p. 631-664, 1987.

EHRLICH, Eugen. Freie rechtsfindung und freie rechtswissenschaft: soziologie und jurisprudenz. Leipzig: Hirschfeld, 1903. 
FANTAPPIÈ, Carlo. Arturo Carlo Jemolo: riforma religiosa e laicità dello Stato. Bréscia: Morcelliana, 2011.

FEDOZZI, Prospero. L'idealità nazionale e il dovere d'Italia. In: DEL VECCHIO, Giorgio et al. La nostra guerra. Firenze: Tipografia domenicana, 1915. (Associazione nazionale fra i professori universitari).

FERRARA, Francesco. Diritto di guerra e diritto di pace. Rivista del diritto commerciale e del diritto generale delle obbligazioni, Milano, v. 16, parte I, p. 682-714, 1918.

FERRARA, Francesco. Influenza giuridica della guerra nei rapporti civili. Rivista del diritto commerciale e del diritto generale delle obbligazioni, Milano, v. 13, parte I, 1915.

FERRI, Enrico. I nuovi orizzonti del diritto e della procedura penale. Bologna: Zanichelli, 1881.

FERRINI, Contardo. Diritto penale romano: teorie generali. Milano: Ulrico Hoepli, 1899.

FERRINI, Contardo. Il Digesto. Milano: Ulrico Hoepli, 1893.

FERRINI, Contardo. Manuale di Pandette. Milano: Società Editrice Libraria, [1900].

FLORIAN, Eugenio. Schema di autobiografia intellettuale. In: FLORIAN, Eugenio et al. Eugenio Florian: maestro del positivismo penale: in occasione del suo commiato dall'Università. Milano: Bocca, 1940.

FLORIAN, Eugenio; ZERBOGLIO, Adolfo. [Programma]. Rivista di diritto e procedura penale, Milano, v. 1, 1910.

FOIS, Giuseppina. Reclutamento dei docenti e sistemi concorsuali, dal 1860 a oggi. In: BRIZZI, Gian Paolo; DEL NEGRO, Piero; ROMANO, Andrea (Org.). Storia delle Università in Italia. Messina: Sicania, 2007. v. 1.

FURGIUELE, Giovanni. La "Rivista di diritto civile" dal 1909 al 1931. Quaderni Fiorentini: per la storia del pensiero giuridico moderno, Milano, v. 16, p. 519-630, 1987.

GAJA, Giorgio. Le prime annate della "Rivista di diritto internazionale" ed il rinnovamento del metodo. Quaderni Fiorentini: per la storia del pensiero giuridico moderno, Milano, v. 16, p. 485499, 1987.

GAJA, Giorgio. Positivism and dualism in Dionisio Anzilotti. European Journal of International Law, v. 3, n. 1, p. 123-138, 1992.

GENTILE, Emilio. La grande Italia. Il mito della nazione nel XX secolo. Roma-Bari: Laterza, 2006.

GIOIA, Vitantonio; NOTO, Sergio (Org.). Angelo Messedaglia e il suo tempo: atti del convegno. Macerata: EUM, 2011.

GIOVANNI CHIODI. In: BIROCCHI, Italo et al. Dizionario biografico dei giuristi italiani. Bologna: Il Mulino, 2013. v. 2, p. 1.833-1.837. 
GIURIATI, Domenico. Arte forense... Torino: Roux e Favale, 1878.

GRAVINA, Giacomo Pace. "Una cattedra nuova di materia nuova": storici del diritto in Italia dall'unità alla grande guerra. In: BIROCCHI, Italo e BRUTTI, Massimo (Org.). Storia del diritto e identità disciplinari: tradizioni e prospettive. Torino: Giappichelli, 2016.

HALPÉRIN, Jean-Louis. In: ARABEYRE, Patrick; HALPÉRIN, Jean-Louis; KRYNEN, Jacques. Dictionnaire historique des juristes français XII ${ }^{e}-X X^{e}$ siècle. Paris: PUF, 2015. p. 960.

IRTI, Natalino. L'età della decodificazione. Milano: Giuffrè, [1979].

JAMIN, Christophe. Le droit des manuels de droit ou l'art de traiter la moitié du sujet. In: CHAMBOST, Anne-Sophie (Org.). Histoire des manuels de droit. Une histoire de la littérature juridique comme forme du discours universitaire. Paris: Lextenso LGDJ, 2014.

JEMOLO, Arturo Carlo. Anni di prova. Firenze: Passigli, 1991.

JEMOLO, Arturo Carlo. Lettere a Mario Falco, t. 2 (1928-1943), a cura di Maria Vismara Missiroli. Milano: Giuffrè, 2009. v. 89 (Per la storia del pensiero giuridico moderno).

LACCHÈ, Luigi. I giuristi italiani e il risorgimento: Una proposta per rileggere la questione della cultura giuridica nazionale e delle "scuole" a partire dal canone eclettico. Rivista italiana per le scienze giuridiche, Napoli, v. 4, p. 317-361, 2013.

LARENZ, Karl. Storia del metodo nella scienza giuridica. Milano: Giuffrè, 1966.

LIBERTINI, Mario. Vivante, Cesare. In: BIROCCHI, Italo, et al. (Org.). Dizionario biografico dei giuristi italiani (XII-XX secolo). Bologna: Il Mulino, 2013. v. 2.

LIBONATI, Bernardino et al. La rivista di diritto commerciale (1903-1922). Quaderni Fiorentini: per la storia del pensiero giuridico moderno, Milano, v. 16, p. 343-374, 1987.

LIEBMAN, Enrico Tullio. Storiografia giuridica "manipolata". Rivista di Diritto Processuale, Padova, v. 29, parte 1, 1974.

LODOVICO MORTARA. In: SALVIOLI, Giuseppe. Manuale di storia del diritto italiano dalle invasioni germaniche ai nostri giorgi. Torino: Inione Tip. Ed., 1890. 2 v.

LUCCHINI, Luigi. I semplicisti (antropologi, psicologi e sociologi) del diritto penale. Torino: Unione Tipografico-Editrice, 1886.

MAGGIORE, Giuseppe. Vita di nessuno: note autobiografiche. Cuneo: Ghibaudo, 1954.

MANARA, Ulisse. Il diritto ferroviario: formazione, carattere, partizione. Archivio Giuridico, [S.1.], v. 40, fasc. 1-2, 1888 .

MANSUINO, Carlo (Org.). Periodici giuridici italiani: 1850-1900: repertorio. Milano: Giuffrè, 1994. 
MARCO PAOLO GERI. In: TAFFON, G. (A cura di) Dizionario biografico degli italiani. Roma: Istituto della Enciclopedia Italiana. v. 88, 2017.

MARINI, Gaetano. Giuseppe Maggiore. L'interferenza di filosofia e diritto. Napoli: Edizioni Scientifiche Italiane, [1983].

MARTONE, Luciano. Il diritto coloniale. In: CAPPELLINI, Paolo et. al. (Org.). Il contributo italiano alla storia del pensiero. Diritto. Roma: Istituto della Enciclopedia Italiana, 2012.

MASI, Antonio. Brugi Biagio. In: VV. AA. Dizionario biografico degli italiani. Roma: Istituto della Enciclopedia Italiana, 2017. v. 88.

MATTIROLO, Luigi. Elementi di diritto giudiziario civile italiano. Torino: Bocca, 1875-80. 6 v.

MAZZACANE, Aldo (Org.). I giuristi e la crisi dello Stato liberale in Italia fra otto e novecento. Napoli: Liguori, 1986.

MAZZACANE, Aldo; SCHIERA, Pierangelo (Org.). Enciclopedia e sapere scientifico: il diritto e le scienze sociali nell’Enciclopedia Juridica Italiana. Bologna: Il Mulino, 1990.

MECCA, Giuseppe. Manuali di scienze giuridiche, politiche e sociali: letteratura universitaria e insegnamento del diritto in Italia tra otto e novecento. In: TORTORELLI, Gianfranco (Org.). Non bramo altr'esca: studi sulla casa editrice Barbèra. Bologna: Pentragon, 2013. p. 157-203.

MENICONI, Antonella. Storia della magistratura italiana. Bologna: Il Mulino, 2012.

MIELE, Manlio (Org.). Gli insegnamenti del diritto canonico e del diritto ecclesiastico dopo l'Unità d'Italia. Bologna: Il Mulino, 2015.

MILETTI, Marco Nicola. La giustizia penale. In: CAPPELLINI, Paolo et. al. (Org.). Il contributo italiano alla storia del pensiero. Diritto. Roma: Istituto della Enciclopedia Italiana, 2012.

MONTI, Annamaria. Angelo Sraffa. Un ‘antiteorico’ del diritto. Milano: Egea, 2011.

MORTARA, Lodovico. Manuale della procedura civile. Torino: Unione Tipografico Editrice, 1906.

MOSSA, Lorenzo. Il diritto del lavoro. Sassari: Stamperia della Libreria italiana e straniera, 1923.

MURA, Eloisa. All'ombra di Mancini: la disciplina internazionalistica in Italia ai suoi albori. Pisa: ETS, 2017.

MURA, Eloisa. Emilio Betti, oltre lo specchio della memoria. In: BETTI, Emilio. Notazioni autobiografiche. [Assago]: Cedam, 2014.

NARDOZZA, Massimo. Manualistica e cultura del codice civile in Italia tra otto e novecento. Roma: Aracne, 2012.

NITSCH, Carlo. Il giudice e la legge. Consolidamento e crisi di un paradigma nella cultura giuridica italiana del primo novecento. Milano: Giuffrè, 2012. v. 96. (Per la storia pensiero giuridico moderno). 
OPPO, Giorgio. Codice civile e diritto commerciale. Rivista di diritto civile, Padova, v. 39, n. 2, p. 221-237, pt. 1, mar./apr. 1993.

ORLANDO, Vittorio Emanuele. Lo stato e la realtà: discorso inaugurale del Prof. Vittorio Emanuele Orlando. Annuario dell'anno scolastico 1910-911. Regia Università degli studi di Roma, Roma, p. 5-31, 1911. p. 18-20.

OSLER, Douglas J. The myth of European legal history. Rechtshistorisches Journal, Frankfurt am Main, v. 16, p. 393-410, 1997.

PARINI VINCENTI, Sara. Un 'vecchio' noi ed un 'nuovo' loro. L'Introduzione enciclopedica allo studio del Diritto di G. D. Romagnosi. Italian Review of legal History, Milano, n. 1, p. 1-16, 2015. Disponibile in: <http://irlh.unimi.it/wp-content/uploads/2017/03/Sara-Parini_2015_1.pdf>.

PASSERO, Laura. Dionisio Anzilotti e la dottrina internazionalistica tra otto e novecento. Milano: Giuffrè, 2010.

PELLICCIOLI, Luca. Natura delle cose e metodo giuridico: il "diritto naturale" dei giuristi. Pisa: ETS, 2015.

PERTILE, Antonio. Storia del diritto italiano dalla caduta dell'impero romano alla codificazione. Padova: Salmin, 1871.

PLANITZ, Hans (Org.). Die rechtswissenschaft der gegenwart in selbstdarstellungen. Leipzig: Meiner, [1923-1925]. v. 1-3.

PROTO PISANI, Andrea. Materiali per uno studio dei contributi processualcivilistici della "Rivista di diritto commerciale" (1903-1923). Quaderni Fiorentini: per la storia del pensiero giuridico moderno, Milano, v. 16, p. 375-440, 1987.

ROCCO, Arturo. Il problema e il metodo della scienza del diritto penale. Rivista di diritto e procedura penale, Milano, v. 1, 1910.

RODOTÀ, Stefano. La libertà e i diritti. In: ROMANELLI, Raffaele (Org.). Storia dello stato italiano: dall'unità a oggi. Roma: Donzelli, 1995.

ROMANO, Santi. Corso di diritto coloniale: impartito nel R. Istituto di Scienze Sociali C. Alfieri di Firenze. Roma: Athenaeum, 1918.

ROMANO, Santi. Lo stato moderno e la sua crisi. Milano: Giuffrè, 1969.

ROSSI, Davide. Storia (e apologia) di una rivista: per i centocinquantacinque anni della Rivista amministrativa. Rivista Amministrativa della Repubblica Italiana, Roma, v. 157, n. 1, 2006.

RUFFINI, Francesco. Guerra e riforme costituzionali. Suffragio universale, principio maggioritario, elezione proporzionale, rappresentanza organica. Annuario della R. Universià di Torino, 19191920, Torino, 1920. 
RUFFINI, Francesco. L'indirizzo odierno del diritto ecclesiastico in Italia. In: . Scritti giuridici minori. Milano: Giuffrè, 1936. v. 1.

SALERNO, Francesco. L'affermazione del positivismo giuridico nella scuola internazionalista italiana: il ruolo di Anzilotti e Perassi. Rivista di Diritto Internazionale, Milano, v. 95, 2012.

SALERNO, Francesco. La rivista e gli studi di diritto internazionale nel periodo 1906-1943. Rivista di diritto internazionale, Milano, v. 90, n. 2, 2007.

SALVI, Cesare. La giusprivatistica fra codice e scienza. In: SCHIAVONE, Aldo (Org.). Stato e cultura giuridica in Italia dall'Unità alla Repubblica. Roma-Bari: Laterza, 1990.

SALVIOLI, Giuseppe. Manuale di storia del diritto italiano. Torino: Unione tipografico-editrice, 1890.

SBRICCOLI, Mario. Storia del diritto penale e della giustizia. Scritti editi e inediti (1972-2007). Milano: Giuffrè, 2009. v. 88, n. 1-2. (Per la storia pensiero giuridico moderno).

SCIALOJA, Vittorio. Diritto e giuristi nel risorgimento italiano. Rassegna contemporanea, Roma, ano 4, n. 10, 1911a.

SCIALOJA, Vittorio. Diritto pratico e diritto teorico. Rivista del diritto commerciale e del diritto generale delle obbligazioni, Milano, v. 9, parte 1, p. 941-948, 1911 b.

SCIALOJA, Vittorio. I problemi dello Stato italiano dopo la guerra. Bologna: Zanichelli, 1918.

SCIALOJA, Vittorio. Per un'alleanza legislativa fra gli Stati dell'Intesa. Nuova Antologia, Firenze, v. 181, fascicolo 1.057, p. 451-452, febbr. 1916. Serie 6.

SCLOPIS DI SALERANO, Federigo. Diario segreto (1859-1878). Torino: Deputazione subalpina di storia patria, 1959.

SPINOSA, Alberto. Storia del diritto e costruzione dell'identità nazionale. In: CAZZETTA, Giovanni (Org.). Retoriche dei giuristi e costruzione dell'identità nazionale. Bologna: Il Mulino, 2013.

SRAFFA, Angelo. La riforma della legislazione commerciale e la funzione dei giuristi. Rivista del diritto commerciale e del diritto generale delle obbligazioni, Milano, v. 11, parte prima, 1913.

STELLA RICHTER, Mario Jr. Persona giuridica e società. In: . Gustavo Bonelli: un giurista in Banca d'Italia (no prelo).

STOLFI, Emanuele. Studio e insegnamento del diritto romano dagli ultimi decenni dell'Ottocento alla prima guerra mondiale. In: BIROCCHI, Italo; BRUTTI, Massimo (Org.). Storia del diritto e identità disciplinari: tradizioni e prospettive. Torino: Giappichelli, 2016.

STOLFI, Emanuele. Vittorio Scialoja. In: VV. AA. Enciclopedia italiana di scienze, lettere ed arti: il contributo italiano alla storia del pensiero. Roma: Instituto della Enciclopedia Italiana. 2012. Appendice 8: Diritto. p. 397-400. 
STOLZI, Irene. L'ordine corporativo: poteri organizzati e organizzazione del potere nella riflessione giuridica dell'Italia fascista. Milano: Giuffrè, 2007. v. 71. (Per la storia pensiero giuridico moderno). STOLZI, Irene. Le inchieste parlamentari. Un profilo storico-giuridico (Italia, 1861-1900). Milano: Giuffrè, 2015. v. 107.

TARUFFO, Michele. La giustizia civile in Italia dal '700 a oggi. Bologna: Il Mulino, 1980.

THALLER, Edmond Eugène. De l'attraction exercée par le code civil et par ses méthodes sur le droit commercial. In: SOREL, Albert. Le code civil 1804-1904: livre du centenaire. Paris: Rousseau, 1904.

TRIFONE, Gian Paolo. Il diritto al cospetto della politica: Miceli, Rossi, Siotto Pintòr e la crisi della rappresentanza liberale. Napoli: Edizioni Scientifiche Italiane, 2010.

TURI, Gabriele. Lo stato educatore: politica e intellettuali nell'Italia fascista. Roma-Bari: Laterza, 2002.

UNGARI, Paolo. Per la storia dell'idea di codice. Quaderni Fiorentini: per la storia del pensiero giuridico moderno, Milano, v. 1, p. 207-227, 1972. p. 210-212.

VASSALLI, Filippo. Della legislazione di guerra e dei nuovi confini del diritto privato. Rivista del diritto commerciale e del diritto generale delle obbligazioni, Milano, v. 17, parte 1, 1919.

VASSALLI, Filippo. In tema di "epurazione” (deduzioni alla commissione ministeriale). Roma: Bardi, 1945.

VASSALLI, Filippo. Motivi e caratteri della codificazione civile. In: VASSALLI, Filippo. Scritti giuridici. Milano: Giuffrè, 1960. v. 3, n. 2.

VASSALLI, Filippo. Scritti giuridici. Milano: Giuffrè, 1960. v. 3, n. 2, p. 605-606.

VIDARI, Ercole. Compendio di diritto commerciale italiano. Milano: Ulrico Hoepli, 1910.

VIORA, Mario Enrico. Indice del cinquantennio (1928-1977). Rivista di storia del diritto italiano, Roma, v. 50, 1977.

VIVANTE, Cesare. Prefazione alla seconda edizione. In: . Trattato di diritto commerciale.

Milano: Vallardi, 1904. v. 3.

VIVANTE, Cesare. Trattato teorico-pratico di diritto commerciale. Torino: F.lli Bocca, 1893-1902. $4 \mathrm{v}$.

VIVANTE, Cesare; SRAFFA, Angelo. Il nostro programma. Rivista di diritto commerciale industriale e marittimo, Milano, v. 1, parte I, 1903, p. I-II.

VV. AA. Dizionario biografico degli italiani. Roma: Istituto della Enciclopedia Italiana, 2017. v. 88. VV. AA. Le prolusioni dei civilisti. Napoli: Edizioni Scientifiche Italiane, 2012. v. 1-3. 
VV. AA. Legittimazione e metodo della scienza penale: a cento anni dalla prolusione sassarese di Arturo Rocco. Criminalia. Annuario di scienze penalistiche, Pisa, 2010.

WIEACKER, Franz. Storia del diritto privato moderno: con particolare riguardo alla Germania. Milano: Giuffrè, 1980. v. 2. 